\title{
ANALYSIS OF THE MICROPHONIC POTENTIAL OF THE BULLFROG'S SACCULUS ${ }^{1}$
}

\author{
D. P. COREY ${ }^{2}$ AND A. J. HUDSPETH ${ }^{3}$ \\ Division of Biology, California Institute of Technology, Pasadena, California 91125
}

Received October 6, 1981; Revised September 9, 1982; Accepted November 23, 1982

\begin{abstract}
The sensory epithelium from the bullfrog's sacculus was mounted between two chambers and stimulated by moving the otolithic membrane with a piezoelectric stimulator. The evoked response was measured as the transepithelial "microphonic" potential or, when the epithelium was voltage clamped, as the microphonic current. Microphonic responses were similar to those recorded in other preparations: the whole organ produced a " $2 \mathrm{f}$ " response (i.e., a response of a frequency twice that of the stimulus) which could be changed to a single-polarity response by stimulating cells of a single polarity; the response saturated asymmetrically with displacement, producing a rectification; and the amplitude declined at high and low frequencies. To determine the cellular elements responsible for generation of the microphonic potential, the equivalent circuit of the epithelium was estimated from morphological and electrophysiological data, and responses to step displacement stimuli were recorded. Four elements in particular shape the microphonic potential: the complex impedance of the extracellular current path, the saturating displacement-conductance curve, an adaptation mechanism which shifts that curve, and a voltage-dependent $\mathrm{K}^{+}$conductance in the basolateral hair cell membrane. A quantitative model incorporating these elements accurately reproduces the observed responses.
\end{abstract}

Over 50 years ago Wever and Bray (1930) recorded from the 8th nerve of cats what they considered to be whole nerve action potentials in response to acoustic stimuli. These potentials duplicated the waveform of the stimulus over a range of 125 to $4100 \mathrm{~Hz}$. The finding was of fundamental importance to sensory physiology, for it challenged the general principle then becoming established (Adrian, 1928) that the frequency of sensory nerve firing is related to the intensity of stimulation. The following year Adrian (1931) presented evidence contesting the origin of the potentials and suggested that they were generated within the cochlea by "some kind of

\footnotetext{
${ }^{1}$ This research was supported by Grants NS-13154 and GM-07616 from the National Institutes of Health and by the William Randolph Hearst Foundation, the Ann Peppers Foundation, the Pew Memorial Trust, and the System Development Foundation. We thank Mr. R. Jacobs for technical assistance, Dr. J. H. R. Maunsell for aid with computer programming, and Ms. C. Katz for patiently dealing with multitudinous versions of the manuscript. Ms. R. A. Eatock, Dr. T. Holton, and Mr. R. S. Lewis kindly provided critical comments on the paper.

${ }^{2}$ Present address: Department of Physiology, Yale University School of Medicine, New Haven, CT 06510.

${ }^{3}$ To whom reprint requests should be sent at Department of Physiology, University of California School of Medicine, San Francisco, CA 94143.
}

microphonic action." In the intervening years it has become clear that these "microphonic potentials" are in fact produced by hair cells in the cochlea and correspond to extracellular current flow through the impedance of the tissue between the recording electrodes.

The generation of the current flow was explained by Davis (1953) with a variable resistance model in which the endocochlear potential, represented as a battery, causes current to flow across the organ of Corti. The current is modulated by a change in the resistance of the mechanosensitive hair cells; the change in current is observed as a positive or negative potential depending on the positions of the recording electrodes. In its most elaborate form (Davis, 1965), the theory specifically establishes as the driving force the potential across the apical hair cell membrane, which is the difference between the (positive) endocochlear and (negative) intracellular potentials. The inclusion of the intracellular potential is particularly important in generalizing the theory to cover other hair cell organs, in which there is little or no standing potential analogous to the endocochlear potential.

In subsequent years, the model has been supported by manipulation of standing cochlear potentials (Honrubia and Ward, 1969) and extended to include capacitive components of the impedance (Schmiedt and Zwislocki, 
1977) and some nonlinearities in resistive components (Geisler et al., 1980).

In this paper we undertake an analysis of the microphonic potential and microphonic current recorded from an in vitro preparation of the bullfrog's sacculus. The arrangement of the sacculus as an epithelial preparation was developed to complement intracellular recording from the same organ (Hudspeth and Corey, 1977). Our analysis does not significantly contradict that of Davis $(1953,1965)$. Rather, the simplification afforded by spatial homogeneities permits extension of the model to include capacitance and time- and voltage-dependent conductances of the cellular elements. The paper endeavors to establish this preparation as one that can provide quantitative information on the process of transduction and, conversely, to illustrate the great care required in proper interpretation of microphonic potentials in all preparations.

\section{Materials and Methods}

Dissection and mounting. Sacculi of adult bullfrogs (Rana catesbeiana) were exposed by a ventral surgical approach and were removed whole into a dish containing an artificial perilymph solution. There the otolithic mass was removed, tissue extraneous to the macula was trimmed away, and the nerve was severed close to the macula. The macula was transferred with a wide-mouth pipette to the experimental chamber, where it was positioned across a 1-mm hole separating upper and lower baths and fixed in place with a plastic washer (Fig. $1 A$ ).

The macula of the bullfrog sacculus is a planar sheet in which are distributed hair cells with orientations arranged around $360^{\circ}$. The orientation, defined as the direction from the stereocilia to the kinocilium of a hair bundle, represents the direction of greatest mechanical sensitivity (Shotwell et al., 1981). Hair bundles in the periphery of the macula, opposite the nerve's insertion, are directed radially outward; those in the macular center are directed inward (Fig. $1 B$ ).

For most experiments the portion of the otolithic membrane near the nerve's insertion was lifted off the underlying hair cells with a sharpened tungsten dissecting needle. An area of otolithic membrane about $200 \times 300$ $\mu \mathrm{m}$ remained attached to perhaps 300 hair cells at the periphery of the macula. This patch was chosen rather than the central patch used in earlier experiments (Corey and Hudspeth, 1979a) because it encompassed a narrower distribution of hair cell orientations, as judged from mapping of kinocilium positions in scanning electron micrographs and from direct observation with differential interference contrast optics of hair cells in living whole maculae. Moreover, the experimental region is that from which intracellular recordings have been made (Hudspeth and Corey, 1977; Hudspeth and Jacobs, 1979; Shotwell et al., 1981).

A thin $(25-\mu \mathrm{m})$ plastic film (Handi-Wrap, The Dow Chemical Co., Midland, MI) with a hole was then positioned over the macula; the hole size, ranging from 300 to $700 \mu \mathrm{m}$ in diameter, was chosen so as to expose only the region of hair cells still attached to the otolithic membrane. A layer of silicone high vacuum grease (Dow Corning Corp., Midland, MI) held the film to the macula and prevented current flow across portions of the epithelium damaged by the holding washer and across most of the unstimulated macula. The loosened part of the otolithic membrane had a tendency to relax back onto the macula; this was prevented by the plastic film. The film also minimized fluid coupling of the stimulus to the detached hair bundles.

Perfusion. The upper and lower baths, each with a

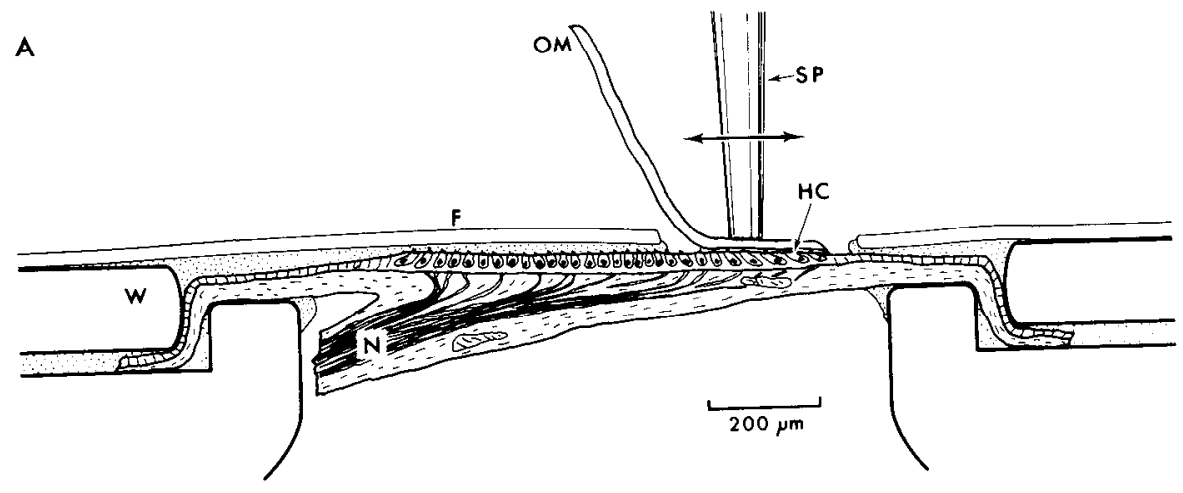

B

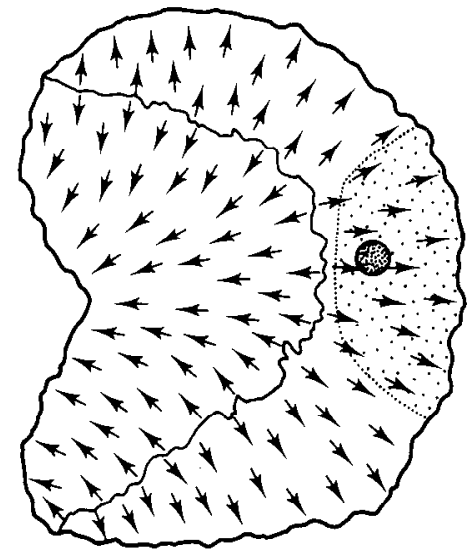

Figure 1. A, Mounting arrangement for the sacculus. The tissue is positioned across a hole between the upper and lower baths, so as to separate them ionically and electrically. The apical surfaces of hair cells $(H C)$ and supporting cells face the upper bath; the basolateral surfaces and the cut nerve $(N)$ face the lower bath. The sacculus is held in place with a 150- $\mu$ m-thick plastic washer $(W)$ and sealed with silicone vacuum grease. For most experiments the otolithic membrane (OM), to which the mechanosensitive hair bundles are normally attached, is peeled up from all but a patch of hair cells in the peripheral macula. These hair cells are stimulated hy moving the overlying otolithic membrane with a glass stimulus probe (SP). A thin (25- $\mu$ m) plastic film $(F)$ restricts transepithelial current flow to the region of the stimulated patch. $B$, Map of hair cell orientations in the saccular macula, obtained from scanning electron micrographs and from direct microscopic observation. Hair cells are most sensitive along an axis from the stereocilia to the kinocilium of a bundle (arrows). The arc across which orientations reverse is termed the striola and is shown as a solid line. In most experiments hair cells are left attached to the otolithic membrane only in a peripheral patch (lightly shaded area) upon which the stimulus probe is placed (heavily shaded area). A displacement of the otolithic membrane from left to right in this figure is defined as positive. 
$0.35-\mathrm{ml}$ volume, were perfused separately with a peristaltic pump, usually at a rate of $1 \mathrm{ml} / \mathrm{min}$. On the assumption of uniform mixing, the time required for $99 \%$ exchange of fluids should have been less than $2 \mathrm{~min}$; this was confirmed by measuring the optical density of fluid near the macula when either bath was perfused with a dilute ink solution.

Solution changes in the upper bath normally exerted their full physiological effects within $2 \mathrm{~min}$, that is, within the wash-in time of the bath. Changes in the lower bath, however, often required 5 to $10 \mathrm{~min}$ for their effects to be seen. The morphology of the epithelium indicates a diffusion barrier between hair cells and the lower bath which would explain this delay (see below).

A thermoelectric temperature control unit maintained the baths within $0.2^{\circ} \mathrm{C}$ of a desired temperature, as determined by a thermocouple sensor (model IT-1, Bailey Instrument Co., Saddle Book, NJ) placed in the upper bath $1 \mathrm{~mm}$ from the macula.

Saline solutions. The $\mathrm{Na}^{+}, \mathrm{Ca}^{2+}$, and $\mathrm{K}^{+}$concentrations of bullfrog endolymph and perilymph were measured with ion-sensitive microelectrodes; details of the measurement will be presented in a separate paper. Solutions used in the top bath are designated endolymphs; those in the bottom are perilymphs. The solutions termed "normal perilymph" and "normal endolymph" (Table I) resemble the naturally occurring fluids in their ionic concentrations, whereas the other solutions are for the most part modifications of these two salines. All solutions contained $3 \mathrm{~mm}$ D-glucose and all were buffered with 5 mM HEPES and adjusted with $\mathrm{NaOH}$ or $\mathrm{KOH}$ to $\mathrm{pH} 7.2$ to 7.3 .

Stimulation. The otolithic membrane was moved with a solid glass probe attached to a piezoelectric bimorph element. Details of the construction and calibration of such stimulators have been presented elsewhere (Corey and Hudspeth, 1980); the stimulator used for these experiments is similar to the device shown in Figure $7 \mathrm{~b}$ of that paper. The tip of the probe, $110 \mu \mathrm{m}$ in diameter, was ground flat and slightly roughened to engage the otolithic membrane. The probe, oscillating in the horizontal plane, was lowered toward the otolithic membrane until a response was seen; when the probe neared the tissue, a vertical displacement of 1 to $3 \mu \mathrm{m}$ sufficed to bring the response from zero to full-sized. Generally the probe was not moved again for the duration of a 3- to 4-hr experiment.

Stimulation consisted of horizontal displacements of

TABLE I

Ionic composition of saline solutions used in analysis of microphonic signals $^{\alpha}$

\begin{tabular}{lcccccc}
\hline & $\begin{array}{c}\text { Normal En- } \\
\text { dolymph }\end{array}$ & $\begin{array}{c}\mathrm{Na}^{+} \text {Endo- } \\
\text { lymph }\end{array}$ & $\begin{array}{c}\mathrm{Cs}^{+} \text {Endo- } \\
\text { lymph }\end{array}$ & $\begin{array}{c}\text { Normal } \\
\text { Perilymph }\end{array}$ & $\begin{array}{c}\text { High } \mathrm{K}^{+} \\
\text {Perilymph }\end{array}$ & $\begin{array}{c}\text { TEA Peri- } \\
\text { lymph }\end{array}$ \\
\hline $\mathrm{Na}^{+}$ & 2.5 & 131.7 & & 119.3 & 108.5 & 119.3 \\
$\mathrm{~K}^{+}$ & 124.0 & & 1.7 & 3.6 & 17.0 & 3.6 \\
$\mathrm{Cs}^{+}$ & & & 130.0 & & & \\
$\mathrm{Ca}^{2+}$ & 0.26 & 0.25 & 0.25 & 1.36 & 1.36 & 1.36 \\
$\mathrm{Mg}^{2+}$ & & & & 0.68 & 0.68 & 0.68 \\
$\mathrm{Cl}^{-}$ & 127.0 & 132.2 & 132.2 & 127.0 & 129.6 & 129.0 \\
$\mathrm{TEA}$ & & & & & & 2.0 \\
\hline
\end{tabular}

a All values are in millimolar concentrations. Each solution also contains $3.0 \mathrm{~mm}$ D-glucose and 5.0 mM HEPES. the probe, either sinusoidal tone bursts or step displacements, usually presented at a rate of $1 \mathrm{~Hz}$. Oscillation of the probe following step displacements was largely eliminated by using as the driving voltage a step with a ramp onset. The ramp had a sigmoidal shape with rise time equal to three-fourths of the period of the resonance (Corey and Hudspeth, 1980); with this driving voltage the displacement was complete within $90 \mu \mathrm{sec}$ and showed transient oscillation of less than $3 \%$ of the step amplitude.

The short length of the bimorph $(4 \mathrm{~mm})$ required that driving voltages be particularly large to obtain reasonable displacements ( $10 \mathrm{~V}$ for a $1-\mu \mathrm{m}$ step). To prevent electrical pickup of the driving signal by the nearby recording circuitry, the bimorph and associated wiring were enclosed in grounded copper shielding with a small exit hole for the glass stimulus probe. Electrical pickup was measured at the end of several experiments by perfusing the upper bath with normal endolymph to which was added $5 \mathrm{mM} \mathrm{Ni}^{2+}$, a potent blocker of the transduction current. Any microphonic current signal in response to probe motion under these conditions was considered to be electrical pickup. A simpler method-measuring the current with the probe lifted off the otolithic membrane-was less satisfactory, as there was some hydrodynamic coupling to the otolithic membrane even with the probe lifted. The measured electrical pickup was always less than $3 \%$ of the response amplitude.

Motion of the probe and of the otolithic membrane was measured optically. Light from a $2-\mathrm{mW}$, helium-neon laser was focused onto a single $60-\mu \mathrm{m}$ glass fiber at one end of an optic fiber bundle; at the other end, the image of that fiber was focused with $\mathrm{a} \times 20$ microscope objective lens to a $10-\mu \mathrm{m}$ spot. The objective lens was held with a micromanipulator in order to position the spot on the object whose motion was of interest. The top and bottom of the experimental chamber were glass coverslips, to provide a continuous light path past the probe and the macula that was unperturbed by an air-saline interface. A condenser lens below the experimental chamber collected the transmitted light and focused it onto a photodiode (PIN-6D, United Detector Technology, Santa Monica, CA). The photocurrent was converted to voltage and amplified; the response time of the circuit, measured with a pulsed light-emitting diode (LED), was $1.5 \mu \mathrm{sec}$. This optical signal was low-pass filtered with a singlepole filter at $20 \mathrm{kHz}$ and a 3 -pole Bessel filter at $50 \mathrm{kHz}$, then digitized at $8 \mu \mathrm{sec}$ per point before averaging.

To measure probe displacement, the light was focused on the edge of the stimulus probe near its tip. Displacements changed the amount of light scattered or absorbed by the probe and thus changed the recorded photocurrent. The linearity of the probe system was confirmed by driving the probe with a slow triangle wave and checking for deviation from linearity in the photocurrent. The amplitude calibration was obtained by observing the probe tip at a magnification of $\times 1000$ in a compound microscope equipped with an eyepiece micrometer, while driving the probe with a square wave signal of known size.

The motion of the otolithic membrane was measured during some experiments by focusing the spot of light on clumps of otoconia adhering to the membrane. For these 
measurements the chamber was positioned on the stage of a compound microscope, through which the macula was viewed at $\times 200$. A portion of the light from the tissue passed through a semisilvered mirror to a camera mounting tube. The free end of the laser-illuminated optic fiber was positioned at the image plane of the tube so that its image was projected back through the microscope optics onto the otolithic membrane. With this arrangement the fiber image could be positioned under visual control on specific clumps of otoconia in the otolithic membrane. The laser light not absorbed or scattered was then collected by the microscope condenser and focused on a photodiode at the illuminator image plane. The preparation was stimulated and recorded from in the normal manner during these measurements.

Recording. The potential across the saccular epithelium was measured with chlorided silver electrodes in the top and bottom baths. Another pair of electrodes was used to pass current across the epithelium. In the clamp mode, the voltage amplifier became part of a voltage clamp circuit which held the potential between the two baths at a fixed value, usually near $0 \mathrm{mV}$. The clamp included series resistance compensation to negate the effects of the series bath resistance. A current-to-voltage converter in the current loop provided an output signal corresponding to the clamp current, and it is this signal that is shown as the response in most figures. The voltage clamp circuit was typical of those used for clamping lowimpedance tissues, such as squid giant axons, with bath electrodes. The head stage of the clamp, placed a few centimeters from the chamber, contained a high-impedance differential amplifier to measure transepithelial potential and a current-to-voltage converter to measure transepithelial current. A portion of the current signal was subtracted from the voltage signal in order to compensate for the series resistance to the chamber and tissue. With the clamp feedback disconnected, square steps of current were passed across the epithelium and the amount of compensation was adjusted so as to remove the step to the charging curve. The voltage clamp feedback was then connected and the clamp gain increased to just below the point of instability. The compensation was adjusted in this way before each set of test stimuli.

The response time of the clamp was measured by placing a passive network equal to the equivalent circuit of the epithelium in the experimental setup at the normal position of the chamber. A photodiode with a 300-nsec response time (model 5082-4220, Hewlett-Packard Co., San Diego, CA) was connected in parallel with the impedance representing the apical hair cell surface and illuminated with a pulsed LED. When the current through the photodiode was increased with a step of light, the clamp settled to $95 \%$ of the final measured current value in 3 $\mu$ sec. It was further found that the response time to a step in command voltage equaled that to a step in photocurrent in the equivalent network; thus the response time to a voltage step was routinely used as a measure of clamp speed during experiments.

The voltage or current signals were low-pass filtered at $10 \mathrm{kHz}$ and the responses to 5 to 100 presentations were averaged by computer. Results are displayed such that clamp currents passing from the upper to the lower bath, which correspond to currents entering the apical hair cell surface, are shown as upward deflections. This convention facilitates the comparison of the present data with those taken by intracellular recording.

Terminology. We use a specific terminology for the various recorded signals both to avoid confusion and to emphasize the similarities to analogous signals in other preparations.

The transepithelial potential is the gross potential measured between the two baths. The microphonic potential is the stimulus-dependent part of it and thus does not include, for instance, steady diffusion potentials. If the transepithelial potential is clamped to a fixed value, the current necessary to do so is the transepithelial current and the microphonic current is the stimulusdependent part of it. The receptor current is the current in a single cell passing through those channels that are opened directly by mechanical stimuli, which we term transduction channels. The receptor potential is, in the strict sense, the change in membrane potential of a single hair cell that results from the receptor current and from consequent voltage- and time-dependent currents. It is this potential that modulates the release of synaptic transmitter.

The displacement-response curve relates displacement of the hair bundle to the response it evokes. Usually the response referred to is the microphonic current, but it may also be the receptor potential (Hudspeth and Corey, 1977) or the equilibrium probability that a transduction channel is open (Corey and Hudspeth, 1983).

Morphology. For electron microscopy, sacculi were removed from frogs and trimmed of extraneous tissue as for recording, but were then fixed for $60 \mathrm{~min}$ at $4^{\circ} \mathrm{C}$ with $2 \%$ glutaraldehyde in $40 \mathrm{~mm}$ sodium phosphate at $\mathrm{pH} 6.8$. After a wash in the phosphate buffer, specimens were postfixed with $1 \% \mathrm{OsO}_{4}$ and then stained with $0.2 \%$ tannic acid. They were dehydrated in ethanol and propylene oxide and embedded in Epon, and the sections were stained with uranyl acetate and lead citrate before being viewed in a Philips 301 microscope at $80 \mathrm{kV}$. Shrinkage caused by fixation was estimated by measuring living preparations in vitro through Nomarski differential interference contrast optics at $\times 1000$.

\section{Results}

\section{Sine wave analysis}

Standing potential. The standing transepithelial potential ranged from 5 to $10 \mathrm{mV}$, endolymph negative, when the baths contained normal endolymph and normal perilymph. Preliminary experiments suggest that this corresponds to the diffusion potential across tight junctions selective for $\mathrm{K}^{\dagger}$; it varies, when other alkali cations are substituted for $\mathrm{K}^{+}$, with a selectivity similar to that displayed by frog gallbladder epithelium (Moreno and Diamond, 1975).

Microphonic current. When the transepithelial potential is clamped to its resting value, the resting transepithelial current is zero. The voltage clamp current evoked by mechanical stimulation is then the microphonic current. Figure 2 shows the microphonic current in response to a "tone" burst comprising three cycles of a 1.0- $\mu \mathrm{m}$ peak-to-peak displacement. The measured current in 


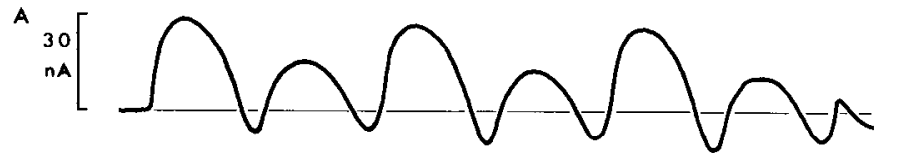

B

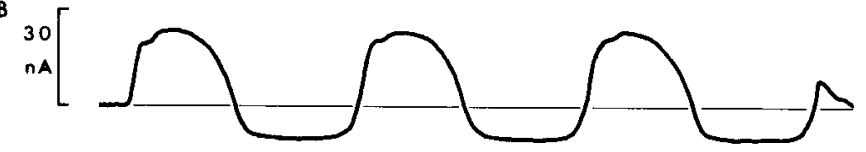

C

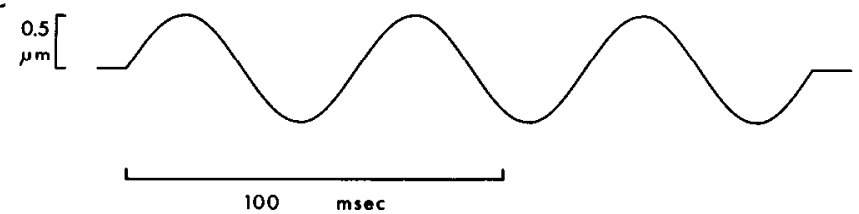

Figure 2. A, Microphonic current generated by the whole macula. $B$, Microphonic current generated by the peripheral patch, from the same preparation as $A$ after peeling back the otolithic membrane. For both, current passing from upper to lower baths, which corresponds to current entering the apical hair cell surface, is shown in the upward direction. $C$, The stimulus is three cycles of a $16.5-\mathrm{Hz}$ sine wave, $1.0 \mu \mathrm{m}$ peak to peak. A positive displacement, from the stereocilia toward the kinocilia for hair bundles in the peripheral macula, is also shown in the upward direction. Normal endolymph and normal perilymph at $21.5^{\circ} \mathrm{C}$ were used.

Figure $2 A$ is the summed response of all hair cells in the macula; that in Figure $2 B$ is the response of the peripheral patch.

The 2 f response. The most conspicuous feature of the response obtained with the otolithic membrane attached to all hair cells of the macula (Fig. $2 A$ ) is that it has a frequency twice that of the stimulus. This " $2 \mathrm{f}$ " response was first recognized by de Vries in the fish lateral line organ, where it was viewed as a full-wave rectification (Jielof et al., 1952). It has since been found in all vertebrate lateral line and otolith organs studied (e.g., Furukawa and Ishii, 1967a; Sand et al., 1975; Kroese et al., 1980). It is not found, however, in semicircular canals or in mammalian cochleas (de Vries and Bleeker, 1949; Tasaki et al., 1954). The morphological basis for this difference was discovered by Lowenstein and Wersäll (1959), who found that hair cells in the skate semicircular canal were of a single orientation, unlike those in lateral line or otolith organs. The generation of the $2 \mathrm{f}$ response was more explicitly described by Flock and Wersäll (1962): they reasoned that hair cells of opposite orientation, each with a nonlinear (rectifying) displacementresponse curve, would sum to produce the double frequency. The hyopthesized nonlinear curve has since been measured in single hair cells (Hudspeth and Corey, 1977).

The summation of oppositely rectificd responses is demonstrated for this preparation simply by lifting the otolithic membrane off the hair cells of one orientation. The response then has the frequency of the stimulus and shows rectification with negative displacements (Fig. $2 B$ ).

Angular sensitivity. In Figure 2B, hair cells are stimulated along their most sensitive axis, but sensitivity along other axes may also be measured. A two-dimensional bimorph stimulator (Corey and Hudspeth, 1980) was used to move the otolithic membrane patch along various axes; the sensitivity to small displacements as a function of angle is shown in Figure 3. The angular sensitivity approximates a cosine relationship (Flock, 1965; Shotwell et al., 1981), indicating a lack of sensitivity to components of the displacement perpendicular to the best axis. Although the sensitivity is somewhat less than predicted by the cosine relation for angles near $0^{\circ}$, it is uncertain whether this is a consequence of the slight spread of orientations within the stimulated patch or whether sensitivity does not precisely follow the cosine of stimulus orientation.

Saturation. Besides the rectification with negative displacements, Figure 2 shows a slight saturation for positive displacements. This lack of a linear response to large stimuli has been found for virtually all hair cell organs (e.g., Jielof et al., 1952; Flock, 1965; Furukawa et al., 1972; Dallos, 1973; Crawford and Fettiplace, 1981b); it is shown in greater detail for this preparation in Figure 4, which plots the response to step displacements of short duration. A fairly sharp saturation occurs with small negative displacements, and a more gradual saturation occurs with positive displacements. A nonlinear transfer curve of this sort acts to generate harmonics in response to sinusoidal stimuli; such harmonics have been measured in mammalian cochleas (Newman et al., 1937; Hubbard et al., 1979). The saturation with large displacements generates odd harmonics, while the asymmetry of the saturation generates even harmonics (Dallos, 1973, p. 395).

Frequency dependence. Finally, Figure 2 shows the current response reaching a peak before the stimulus has peaked. If the response is instead measured as the microphonic potential, the same phase lead is seen at low frequencies, but it becomes a phase lag at high frequencies (Fig. 5). At either extreme, the amplitude of the microphonic potential is reduced. The frequency sensitivity of both phase and amplitude can be fitted by treating the sacculus as a bandpass filter, with first-order slopes $(6 \mathrm{~dB} /$ octave $)$ at both low and high frequencies, and half-power frequencies $(-3 \mathrm{~dB})$ at 25 and $220 \mathrm{~Hz}$, respectively. Bandpass filtering of this sort, particularly

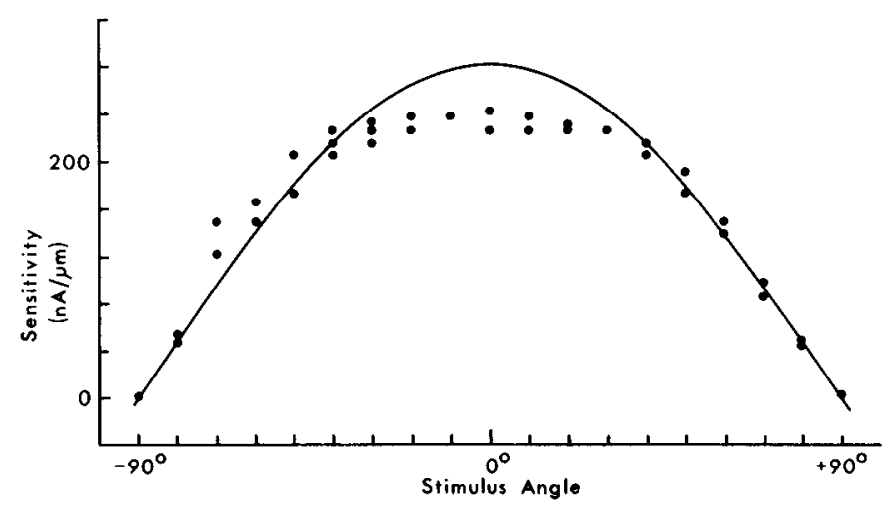

Figure 3. Angular sensitivity of a peripheral patch of macula. The stimulus was a $1.0-\mu \mathrm{m}$ peak-to-peak, $10-\mathrm{Hz}$ triangle wave; $0^{\circ}$ corresponds to the usual positive displacement. The measured response was the microphonic current low-pass filtered at $18 \mathrm{~Hz}$; the plotted sensitivity is the maximum slope of the response in nanoamperes per micrometer. This measure of sensitivity should avoid errors caused by saturation of the transduction mechanism. The curve is proportional to the cosine of stimulus angle and is scaled to fit the sensitivity for large positive and negative angles. Normal endolymph and normal perilymph at $22.0^{\circ} \mathrm{C}$ were used. 


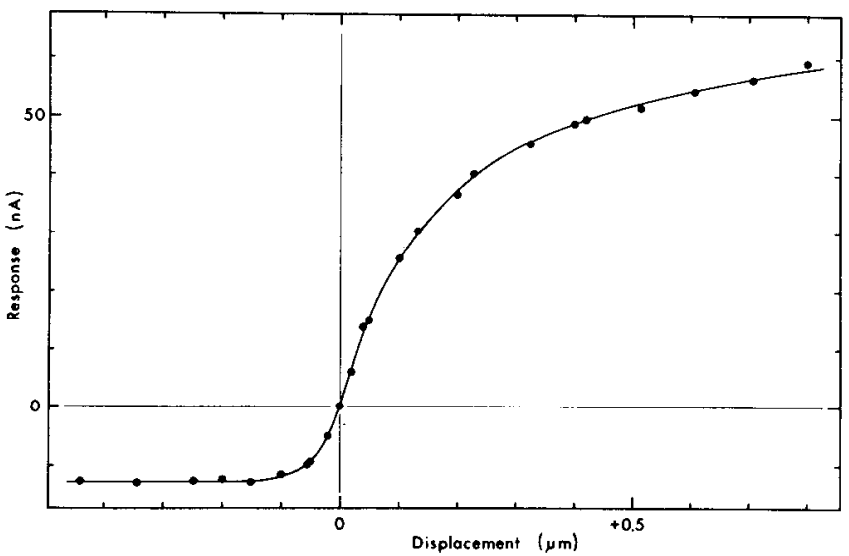

Figure 4. "Instantaneous" displacement-responsc curve of a peripheral patch, from the same preparation as in Figure 2. The stimuli were steps $2 \mathrm{msec}$ in duration and of various amplitudes. The transepithelial current, recorded with the voltage clamp and series resistance compensation, was measured about 100 $\mu$ sec after the rise of the step, when the current had settled to the new value (see Fig. 2 of Corey and Hudspeth, 1983). The intracellular potential changes negligibly during this time; thus this curve excludes the complications of time- and voltagedependent conductance changes that are secondary to the intracellular receptor potential. The curve was drawn through the data points by eye. Normal endolymph and normal perilymph at $21.5^{\circ} \mathrm{C}$ were used.
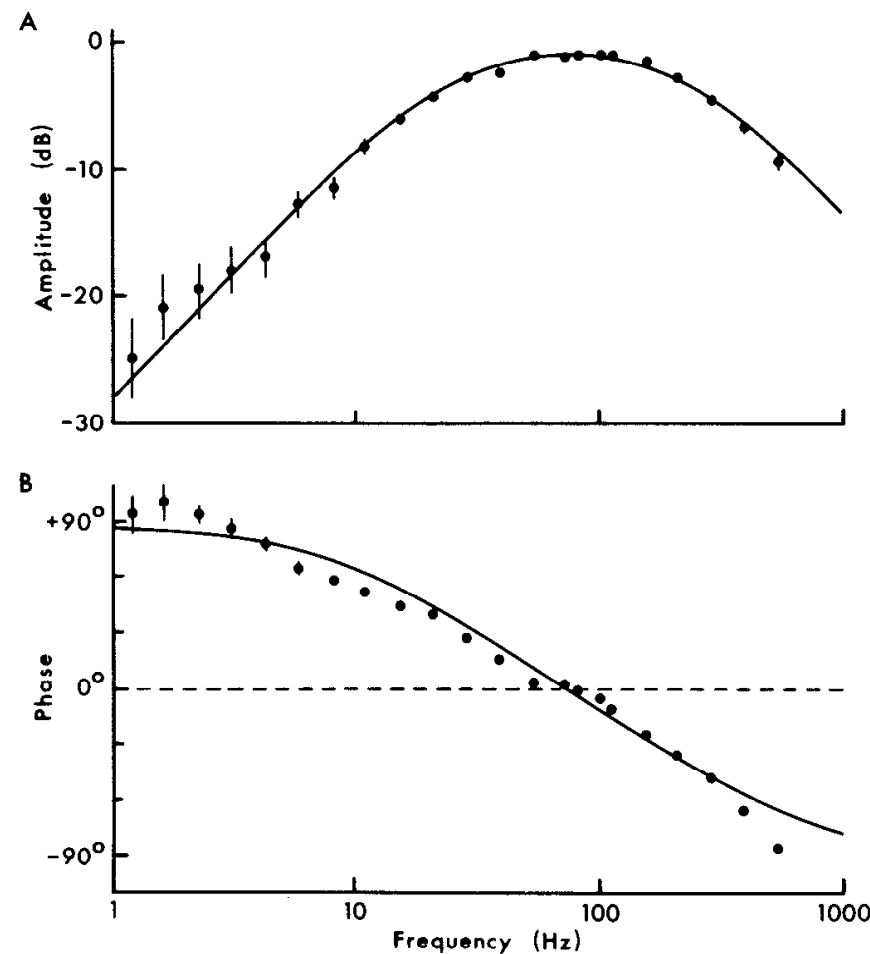

Figure 5. Frequency dependence of the microphonic potential. A $0.3-\mu \mathrm{m}$ peak-to-peak sine wave was presented to the whole macula. $A$, Amplitude was measured after correcting for the rectification occurring with negative displacements, and is plotted as $\log$ (amplitude) on a decibel scale relative to the maximum response $(0 \mathrm{~dB})$. $B$, Phase was measured as the position of the larger of the two peaks relative to the peak of the sine wave stimulus; positive phase is a phase lead. The two curves are calculated for a bandpass filter with first-order low and high frequency slopes and half-power frequencies at 25 and $220 \mathrm{~Hz}$, respectively. Normal endolymph and normal perilymph at $22.5^{\circ} \mathrm{C}$ were used. the high-pass characteristic, has been noted in many other hair cell organs (Jielof et al., 1952; Furukawa and Ishii, 1967b; Kroese et al., 1980). When the response is measured with a voltage clamp as the microphonic current, the high-pass characteristic is present, but the lowpass is not; the response amplitude does not decline at high frequencies.

Step response. A transfer function for the sacculus that can be described in the frequency domain as a first-order high-pass filter should produce a characteristic response when studied in the time domain. Following a step displacement of the otolithic membrane, the response should rise rapidly to a new level and then relax exponentially to zero with a time constant equal to $1 /\left(2 \pi f_{\mathrm{o}}\right)$, where $f_{0}$ is the low frequency half-power point. The actual behavior of the preparation is shown in Figure 6, in which $A$ is the response of the whole macula and $B$ is the response after detaching the otolithic membrane from cells of one orientation.

The responses, particularly as shown in Figure $6 B$, are not quite as expected. The decline is not a simple exponential, there is an additional bump on the falling phase, and the undershoot following the step is not a simple negative step with relaxation. The steady-state responses to sine wave stimuli do not adequately predict the response to a step; a bandpass filter apparently is not a satisfactory description of the transfer function.

Instead, it may be that analysis in the frequency domain is not the best way to study some aspects of transduction in hair cells. The nonlinearities already apparent (Fig. 4) are not conveniently treated by considering them as harmonic sources. Moreover, the biological processes yet to be elucidated are likely to be neither linear nor memoryless. For the remainder of this paper, our purpose will be to describe the response to a step displacement (Fig. $6 B$ ) in terms of time- and voltagedependent cellular processes.

\section{Equivalent circuit of the macular epithelium}

In order to understand how conductance changes affect the step response, one must first understand current paths in the epithelium. We begin by estimating values

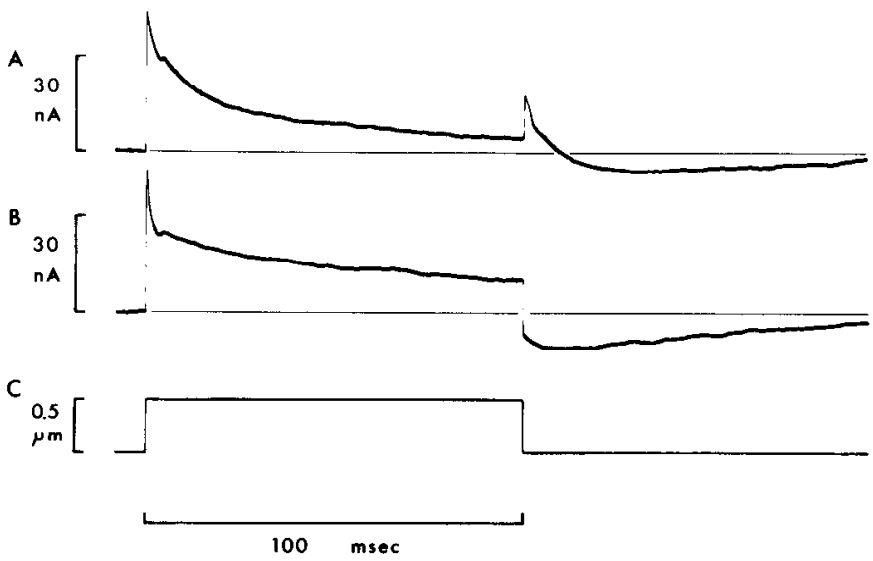

Figure 6. A, Microphonic current generated by the whole macula in response to a step displacement stimulus. $B$, Microphonic current generated by a peripheral patch; both $A$ and $B$ are from the same preparation as in Figure 2. $C$, The stimulus is a $100-\mathrm{msec}$ step of $0.5 \mu \mathrm{m}$ amplitude. Normal endolymph and normal perilymph at $21.5^{\circ} \mathrm{C}$ were used. 
for the parameters in the equivalent circuit of the epithelium from measurements of electron micrographs and from intracellular recording.

Morphology. Figure $7 A$ shows a cross-section of the macular epithelium. The epithelium is composed of hair cells and supporting cells, occurring in roughly a 1:2 ratio. The apical (mucosal or luminal) surfaces of hair cells and supporting cells face the endolymph of the sacculus in vivo or the upper bath of the chamber in vitro. Apical surfaces are ringed with tight junctions (unpublished observations), which constitute the principal diffusion barrier of the epithelium. Supporting cells extend to the bottom of the epithelium, where their basal surfaces tessellate the bottom (serosal) surface of the epithelium. An extracellular basal lamina lies beneath the basal surfaces of supporting cells, but it is not thought to be a significant diffusion barrier for small ions. Immediately above the basal lamina, the lateral surfaces of supporting cells are very closely apposed, running within about 20 $\mathrm{nm}$ of each other over 2 to $5 \mu \mathrm{m}$. In this region there are, as well, numerous and extensive gap junctions between supporting cells (unpublished observations). The close apposition most likely does constitute a significant diffusion barrier. As hair cells do not extend to the bottom of the epithelium, their basolateral surfaces are enclosed within a space, here termed the peribasal space, bounded by tight junctions at the top and the close apposition of supporting cells at the bottom. The restricted access to this space is expected to cause the same complications for current flow and for ionic equilibration as do the Ttubule system of skeletal muscle (Standen and Stanfield, 1979), the periaxonal space of squid axon (Taylor et al., 1980 ), and the membrane infoldings of pacemaker cells in Aplysia (Eaton, 1972). Below the basal lamina lie myelinated nerve fibers and associated connective tissue, which are not expected to present a significant barrier to diffusion. The otolithic membrane above the epithelium, laced as it is with holes above the hair cells (Corey and Hudspeth, 1979a), is also not a barrier.

Equivalent circuit. The cellular elements of the epithelium can be reduced to equivalent resistances and capacitances (Fig. 7, $B$ and $C$ ) representing the various cell surfaces and diffusion barriers. Table II provides estimates of values for each of these components. To facilitate comparison with other preparations, values are given per cell and per unit area of epithelium. Resistances are calculated from measurements of single cells made with intracellular electrodes (Corey and Hudspeth, 1979b and unpublished observations) or of bulk electrical properties of the epithelium. Capacitances are estimated from morphological analysis of membrane surface areas and are confirmed by electrophysiology. We have placed the
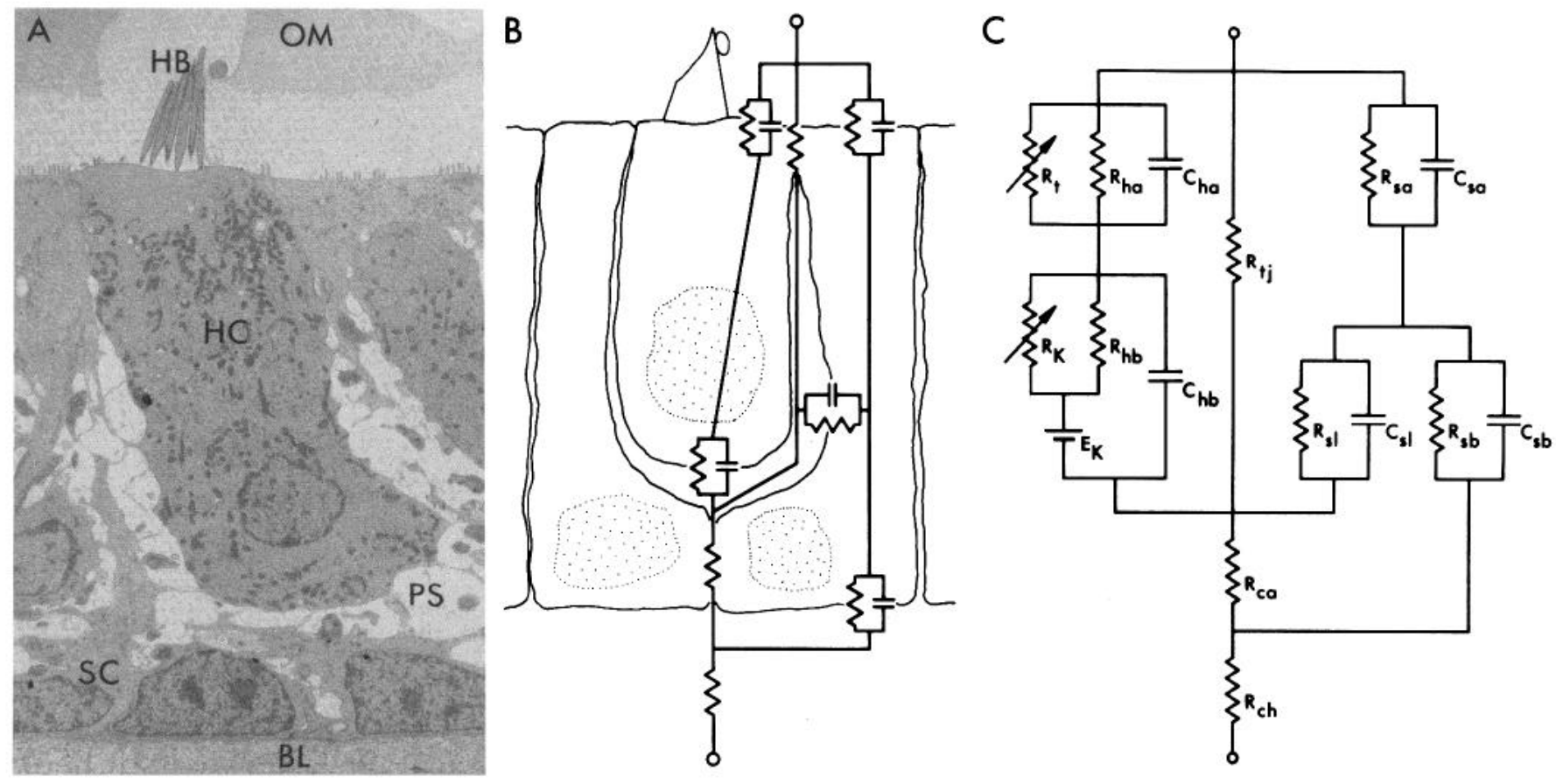

Figure 7. Equivalent circuit of the epithelium. $A$, Transmission electron micrograph showing a small portion of the macular epithelium. Magnification $\times 2000$. $B L$, basal lamina; $H B$, hair bundle; $H C$, hair cell; $O M$, otolithic membrane; $P S$, peribasal space; $S C$, supporting cell. $B$, A cross-sectional representation of the epithelium, showing only those elements thought to present an impedance to current flow. Superimposed is an electrical schematic representation which includes the resistance and capacitance of cell membranes and the resistance of narrow intercellular spaces and junctions. The schematic diagram also includes a resistor representing the series access resistance of the chamber. $C$, The electrical schematic diagram is redrawn to clarify the circuit; symbols are given for each element. The resistances of apical and basal surfaces are separated into leakage $\left(R_{h a}\right.$ and $\left.R_{h b}\right)$ and variable $\left(R_{t}\right.$ and $\left.R_{\mathrm{K}}\right)$ components. The resistances of the basolateral hair cell surface, $R_{h b}$ and $R_{\mathrm{K}}$, are in series with the potassium Nernst potential, $E_{\mathrm{K}}=-84 \mathrm{mV}$. Since the reversal potential for both leakage and receptor currents through the apical membrane is $\sim 0 \mathrm{mV}$, no battery is shown for the apical hair cell surface, nor is a battery shown for any of the supporting cell surfaces: while there is probably a steady current through supporting cells, the modulation of this current by changing hair cell resistances is negligible. 
mechanically activated conductance in the apical membrane of the hair cell. Several lines of evidence support this choice. Intracellular recording from voltage-clamped hair cells reveals a conductance increase occurring with positive bundle displacements (Corey and Hudspeth, 1979b), so the receptor current is inward at the resting potential. The transepithelial voltage clamp shows an increase in current from top to bottom with stimulation (Figs. 2 and 6); thus the receptor current must enter the apical hair cell surface. Also, the microphonic current is blocked by removal of permeant ions from the upper bath, but not from the lower bath. The latency of the response is just $40 \mu \mathrm{sec}$ at room temperature (Corey and Hudspeth, 1979a). A second messenger could not diffuse from the stereocilia to the basolateral membrane in this short time, and there is no morphological evidence for a mechanical linkage to the basolateral surface. Finally, a net current sink near the hair bundle's tip has been demonstrated by extracellular recording (Hudspeth, 1982).

Behavior of the equivalent circuit. Several of the values estimated above can be checked by passing a step of current across the epithelium and measuring the resulting potential. For this rough measurement, several of the circuit elements do not affect the response. The hair cell apical and basal membranes, in series with each other, are together in parallel with the tight junctions. As the hair cell resistance is much larger than the tight junction resistance, the former element is negligible. By the same reasoning, all of the supporting cell resistance elements are negligible. The supporting cell basal capacitance is much less than the (virtually) parallel lateral capacitance; thus we can neglect it also. The resulting circuit, lumping the series/parallel membrane capacitances to form an epithelial capacitance $\left(C_{e}\right)$, is shown in Figure $8 \mathrm{~A}$. If the transepithelial current is stepped from 0 to $i$, we expect a voltage step equal to $i\left(R_{c h}+R_{c a}\right)$, followed by exponential charging to $i\left(R_{c h}+R_{c a}+R_{t j}\right)$ with a time constant $R_{t j} C_{e}$.
The predicted and experimentally measured curves are shown in Figure $8 B$. The form is generally as expected, but with differences in detail. First, the time constant of the experimental curve is shorter than predicted, 320 $\mu$ sec compared to the predicted $390 \mu \mathrm{sec}$, and the final amplitude is smaller. In fact, the time constant and the apparent value of $R_{t j}$ are quite variable among preparations and are inversely correlated with the difficulty of the dissection. This suggests variability in tight junctional integrity, either naturally occurring or experimentally induced.

Second, the charging curve is not purely exponential, but contains a fast (roughly 100-usec) component accounting for about $10 \%$ of the total amplitude. While a significant deviation from a single time constant is not predicted by either the simplified or the full equivalent circuit, two other factors might explain it. First, we have treated the macula as a homogencous epithelium. If there were a difference between areas, then the measured charging curve would be a sum of curves with different time constants. Alternatively, our equivalent circuit might be inadequate in describing diffusion barriers. A close apposition between hair cells and supporting cells would cause a distributed resistance in the peribasal space; this in turn would cause a distributed time constant for charging membrane capacitances (Clausen et al., 1979). These differences in detail are of little consequence here.

The experiment confirms that the bulk of the epithelial impedance is in parallel with the hair cells. As the series hair cell resistance $\left(R_{h a}+R_{h b}\right)$ is much larger than the tight junctional resistance, the hair cell can be modelled as a current source (Fig. $8 A$ ). We can thereby separate factors governing the generation of the hair cell current from the effect the current has on the transepithelial potential.

The microphonic potential can now be predicted for the case in which the current is generated by hair cells rather than by external electrodes. A step displacement

TABLE II

Estimates of values for components of the equivalent circuit of the saccular macula

All values are calculated for a temperature of $22^{\circ} \mathrm{C}$, a macula $0.0035 \mathrm{~cm}^{2}$ in area, a hair cell density of $8.6 \times 10^{5} \mathrm{~cm}^{-2}$, and a supporting cell density of $1.7 \times 10^{6} \mathrm{~cm}^{-2}$. The area of a hair cell's apical membrane surface, including the stereocilia and kinocilium, is roughly $3.6 \times 10^{-6} \mathrm{~cm}^{2}$; the basolateral area is $20.0 \times 10^{-6} \mathrm{~cm}^{2}$. The calculated normal resting potential is $-58 \mathrm{mV}$. Components are identified in Figure 7 .

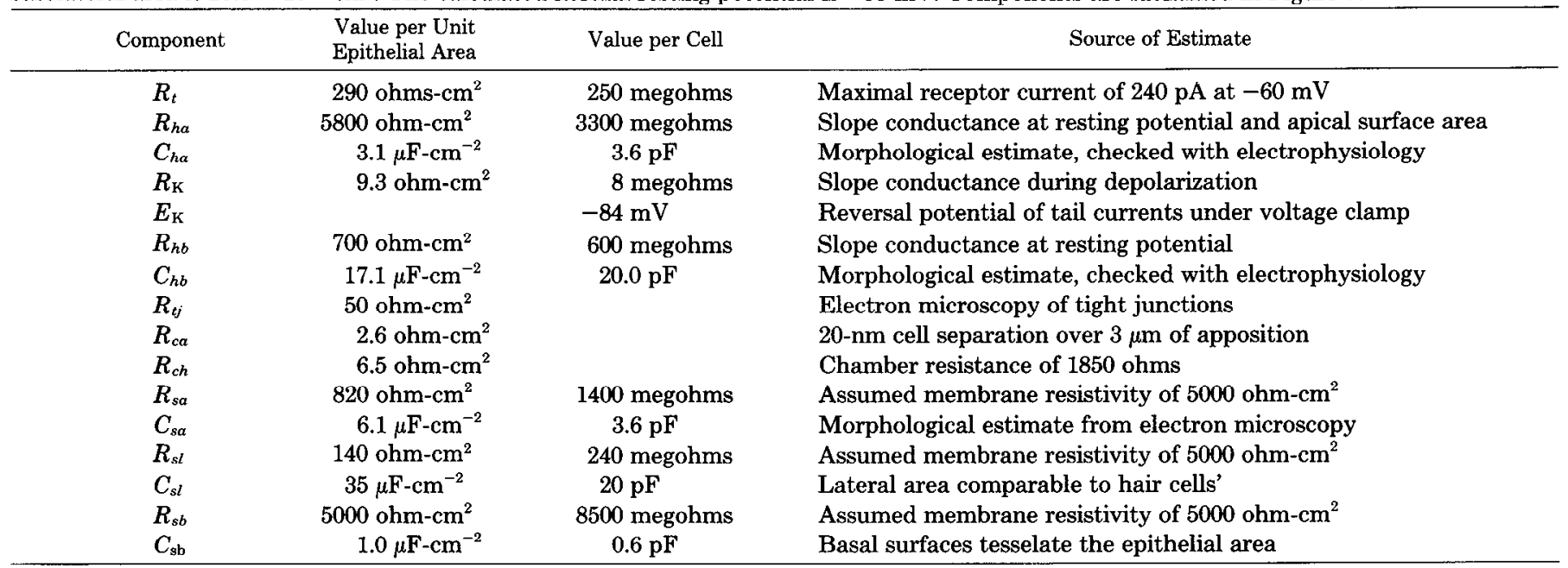


A

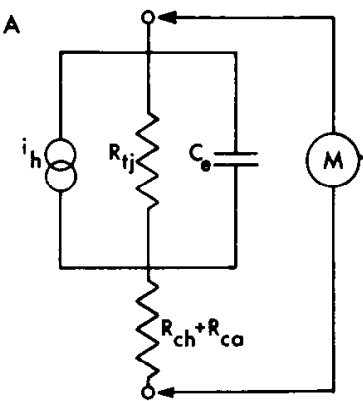

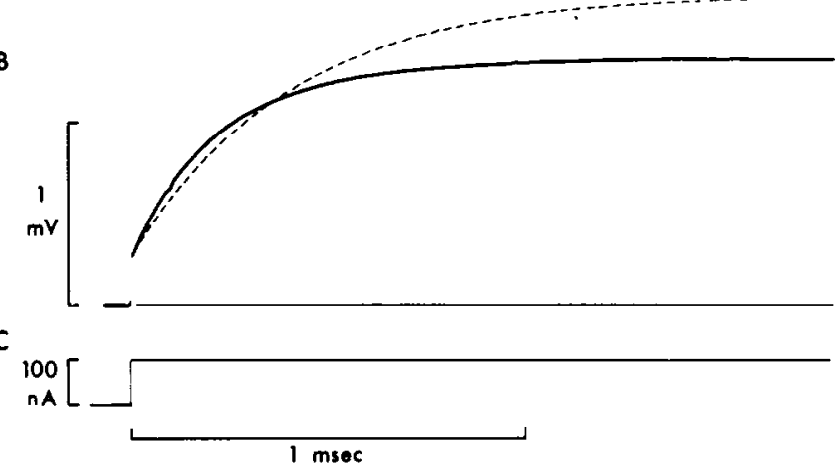

Figure 8. Testing the simplified equivalent circuit. $A$, The equivalent circuit of Figure 7 is condensed to four elements. The net current generated by hair cells can be approximated as a current source $i_{h}$ with infinite series resistance because the tight junctional resistance, $R_{t j}$, is much lower than the parallel resistance of supporting and hair cells. $C_{e}$ represents the lumped capacitance of supporting and hair cells. The series access resistance of the chamber, $R_{c h}$, and the resistance of the close supporting cell apposition, $R_{c a}$, are in series and thus are represented as a single summed element. The generalized meter, $M$, measures from the upper bath to the lower. It is a voltmeter for the measurement of $B$, but can represent a voltage clamp (essentially an ammeter) or a compensated voltage clamp (an ammeter placed across $R_{t j}$ ). $B$, The voltage across the epithelium is measured in response to an applied transepithelial current step $(C)$. For both traces in $B$, the initial voltage step corresponds to the $i R$ drop across $R_{c a}+R_{c h}$; the subsequent approach to steady state corresponds to the charging of $C_{e}$. The solid curve is the experimentally measured curve; the dashed curve is the response of the equivalent circuit in $A$. The general form of both curves is the same; there is in fact more variation among experimentally measured curves than between these two. Normal endolymph and normal perilymph at $22.0^{\circ} \mathrm{C}$ were used.

of hair bundles causes an increase in receptor current within about $50 \mu \mathrm{sec}$ (Corey and Hudspeth, 1983); this current $\left(i_{h}\right)$ flows in through the apical hair cell surface and out through the basolateral surface. Following such a step increase in the hair cell current, the microphonic potential shows the same charging curve as was generated by passing current (time constant $\tau=C_{e} R_{t j}$ ), but without the initial step (Fig. 9A). The potential reaches a steady-state value of $i_{h} R_{t j}$ (Fig. $9 B$ ). If the hair cell current varies sinusoidally, the microphonic potential is reduced for frequencies near or above $f_{\mathrm{o}}=1 /(2 \pi \tau)$. The charging of the epithelial capacitance thus accounts for much of the low-pass filtering in the frequency response of the microphonic potential.

The hair cell current does not remain constant following a step change in conductance, however. As the receptor current depolarizes the hair cell, the driving force for the receptor current decreases. The rate of decline is governed by the membrane time constant, $\tau_{h}=\left(C_{h a}+\right.$ $\left.C_{h b}\right) /\left(1 / R_{h a}+1 / R_{h b}\right)$, which under normal recording circumstances ranges from 1.3 to $12 \mathrm{msec}$ depending on the membrane conductances that are active. As will be shown below, this decrease in the driving force causes the fast decline in the response to a step displacement (Fig. $9 B$ ); it is partially responsible for the high-pass filtering shown in Figure 5.

Under voltage clamp conditions, the top bath is functionally short-circuited to the bottom bath, and we measure the current through this shunt. The clamp thus puts the summed close apposition and chamber resistances $\left(R_{c a}+R_{c h}\right)$ in parallel with the tight junctions $\left(R_{t j}\right)$ and consequently reduces the effective epithelial time constant from 390 to about $60 \mu \mathrm{sec}$ (Fig. $9 \mathrm{C}$ ). At short times, as before, all of the hair cell current passes through the epithelial capacitance; none is measured by the clamp.
At long times ( $>>60 \mu \mathrm{sec}$ ), the hair cell current is divided between the two resistive paths. The ratio of currents is equal to the ratio of conductances; thus the clamp measures a fraction $R_{t j} /\left(R_{t j}+R_{c a}+R_{c h}\right)$, about $85 \%$, of the current through the hair cell. The waveform at long times, however, is nearly identical to that of the microphonic potential (Fig. 9D).

If the value of the series resistance $\left(R_{c a}+R_{c h}\right)$ is known, the clamp can be adjusted to subtract the potential drop caused by current flow across that element. The effect is to clamp directly across $R_{t j}$. With series resistance compensation, the time constant of the epithelium is nominally zero (Fig. $9 E$ ), and the clamp measures all of the hair cell current (Fig. $9 F$ ).

By the foregoing analysis we can partition the step response into two temporal domains. For times that are long compared to the epithelial time constant $(>1 \mathrm{msec})$, the epithelial capacitance is negligible: we see the effects of the changing hair cell membrane potential and of other slow processes within hair cells. These are the subject of the remainder of this paper. For times that are short compared to the hair cell time constant ( $<1 \mathrm{msec})$, the driving force for the receptor current is almost unchanged. The microphonic potential principally shows the charging of the epithelial capacitance; the microphonic current, if measured with a compensated clamp, reflects solely the displacement sensitivity and time dependence of the transduction channels. These are the subject of the following paper (Corey and Hudspeth, 1983).

\section{Dissecting the step response}

The equivalent circuit has given us an explanation of one part of the step response: the rapid drop from the initial peak may be due to the decrease in driving force 

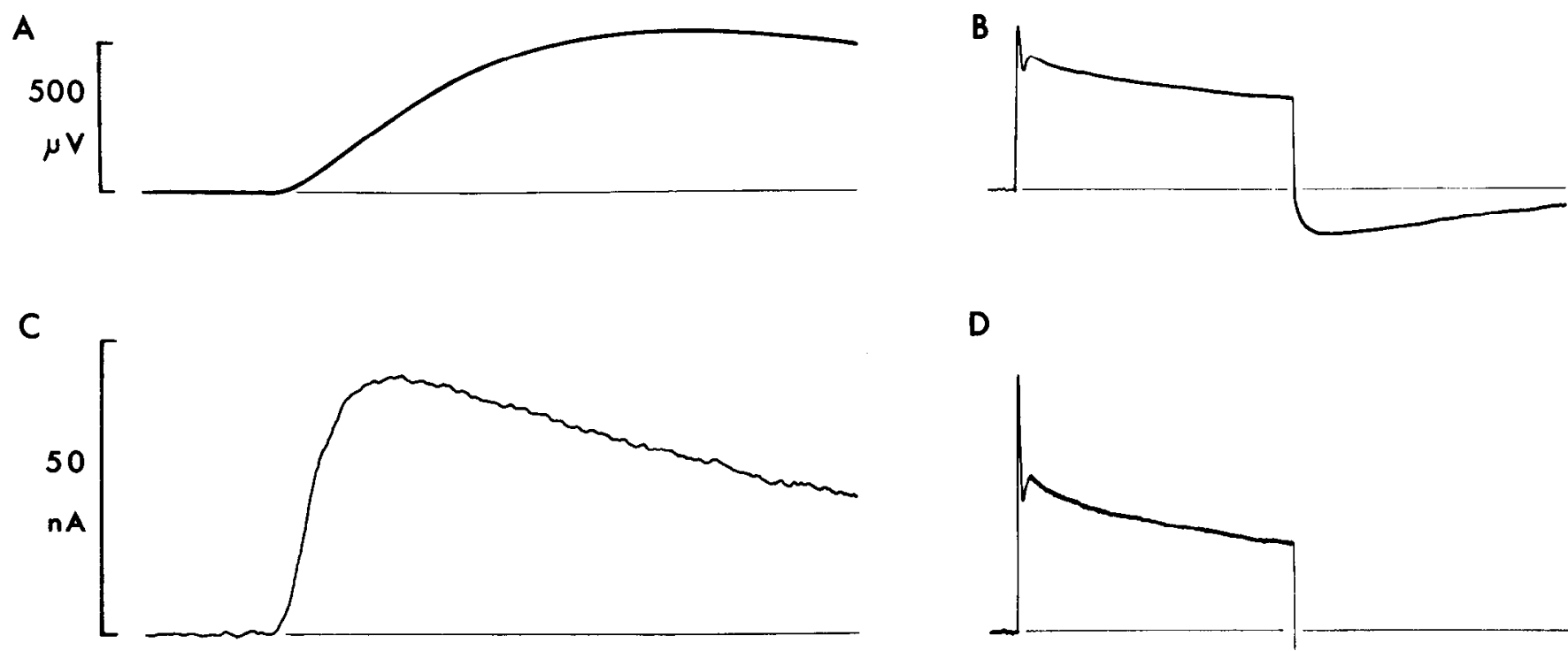

D
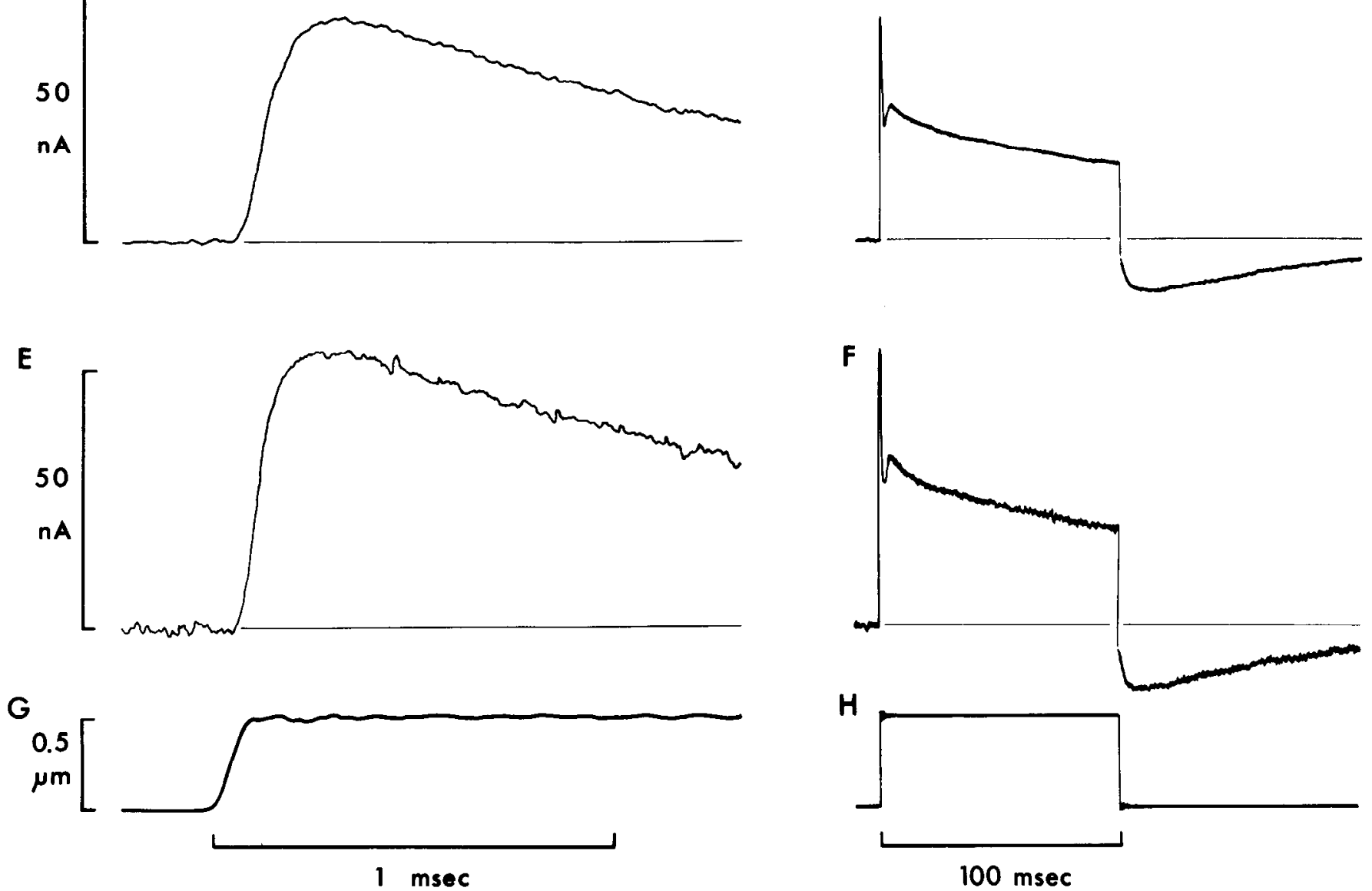

$100 \mathrm{msec}$

Figure 9. The microphonic response to a $0.5-\mu \mathrm{m}$ step displacement; the motion of the stimulus probe is shown at the bottom of each column $\left(G\right.$ and $H$ ). $A$ and $B$, The microphonic potential measured across the epithelium has an amplitude equal to $i_{h} R_{t j}$ at long times $(B)$; immediately after the stimulus begins $(A)$ it shows an exponential charging curve with a time constant $\tau=$ $C_{e} R_{t j}$. The potential is referenced to a ground in the upper bath. $C$ and $D$, The microphonic current measured by voltage clamping across the epithelium is somewhat less than $i_{h}$ : the series resistance reduces it to $i_{h} \cdot R_{t j} /\left(R_{c h}+R_{c a}+R_{t j}\right)$. At short times $(C)$, the recorded current approaches steady state with a time constant (in theory) of $\tau=C_{e} /\left[1 / R_{t j}+1 /\left(R_{c a}+R_{c h}\right)\right] \simeq C_{e} /\left(R_{c a}+R_{c h}\right)$; in practice the finite risetime of the probe and the opening of transduction channels prolong the rise. $E$ and $F$, The microphonic current measured with a series resistance-compensated voltage clamp measures all of the hair cell current $i_{h}$ with negligible delay. The fast rising phase now directly reflects the opening rate of transduction channels, distorted only by the finite risetime of the probe. Normal endolymph and normal perilymph at $22.0^{\circ} \mathrm{C}$ were used.

as the hair cell depolarizes. This idea may be tested by changing the stimulus amplitude. We expect small displacements to produce a small receptor potential in the hair cell and, consequently, to change the driving force very little. The initial drop should be minimal for small displacements; this is shown in Figure 10. The response to a small step has a smooth, slow decline following the fast rise and a nearly symmetrical fall and recovery at the end of the step, actually much like the prediction based on the high-pass filter characteristics. A similar response is seen even with large displacements when $\mathrm{K}^{+}$ in the endolymph is replaced with a poorly permeant cation which causes a smaller receptor potential.

Similarly, the bump occurring 2 to $3 \mathrm{msec}$ after the rapid drop is absent in the small-step response, suggesting that this change in current is also a function of the depolarization occurring in the hair cell. An obvious possibility is a voltage-sensitive potassium conductance, located in the basolateral hair cell membrane, which turns on with some delay following a depolarization. A conductance of this sort has been measured by intracellular voltage clamping of single cells (Corey and 

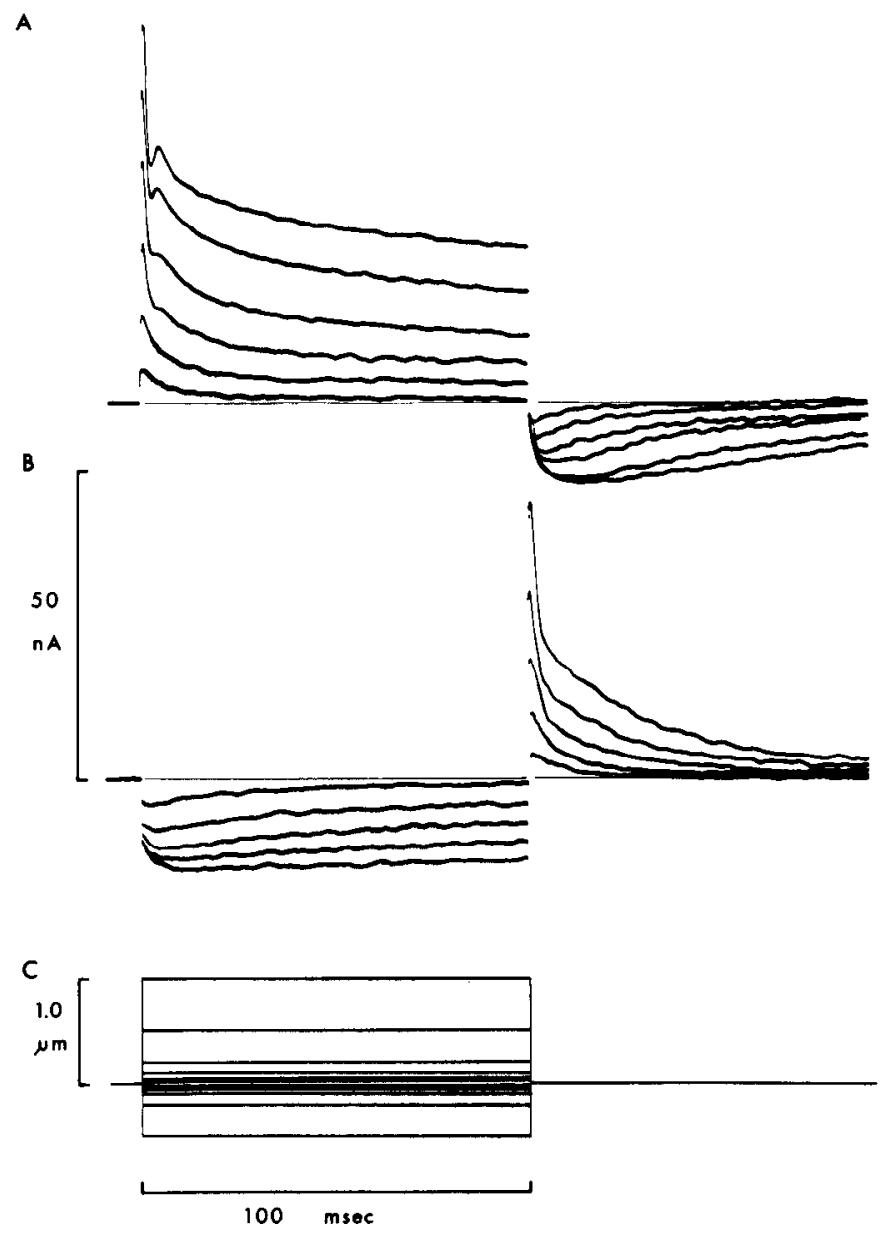

Figure 10. Amplitude dependence of the step response for microphonic current with an uncompensated voltage clamp. $A$, Responses to positive displacements of $0.02-, 0.05-, 0.1-, 0.2-$, $0.5-$, and $1.0-\mu \mathrm{m}$ amplitude. The response amplitudes do not change linearly with displacement, as was seen in the displacement-response curve of Figure 4. $B$, Responses to negative displacements of the same amplitudes as in $A$. The responses show the expected negative saturation, but also show recovery from saturation and a rebound effect following termination of the step. $C$, Probe displacements for $A$ and $B$.

Hudspeth, 1979b). This conductance may be thought of as causing an increase in outward $\mathrm{K}^{+}$current through the basolateral membrane, thereby increasing the measured microphonic current; alternatively, it may be considered as repolarizing the hair cell membrane, thereby increasing the driving force and thus the receptor current.

If such a $\mathrm{K}^{+}$conductance exists in hair cells, we might be able to block it with tetraethylammonium ion (TEA); this is shown in Figure 11. With TEA in the lower bath, the initial fast drop simply continues, reaching a plateau of about 0.3 times the original current. The inference is that the membrane potential during the step is much closer to zero under these conditions: the receptor current has depolarized the cell to perhaps $-20 \mathrm{mV}$, since the rectification which would normally hold it below $-50 \mathrm{mV}$ has been largely blocked. The effect can be duplicated with $5 \mathrm{~mm}$ 3,4-diaminopyridine in the lower bath or by replacing $\mathrm{K}^{+}$with $\mathrm{Cs}^{+}$in the endolymph. We have shown that $\mathrm{Cs}^{+}$passes readily through the transduction channels (Corey and Hudspeth, 1979b); as it accumulates inside the cell, it apparently blocks $\mathrm{K}^{+}$channels from the inside, as it is known to do in squid axon and frog nerve (Bezanilla and Armstrong, 1972; Hille, 1973).

The converse experiment is to hold the hair cell membrane potential constant. An elevated $\mathrm{K}^{+}$concentration in the lower bath should depolarize hair cells. If the resting potential is moved above the activation potential of the $\mathrm{K}^{+}$conductance, then this conductance should make the input resistance quite small, and the receptor current should cause little change in the membrane potential. In a sense, we are starting with the conditions normally reached after the bump. Now the step response does not show the fast drop and bump phenomenon (Fig. 12): there is presumed to be little change in the driving force and thus no delayed activation of voltage-depend-

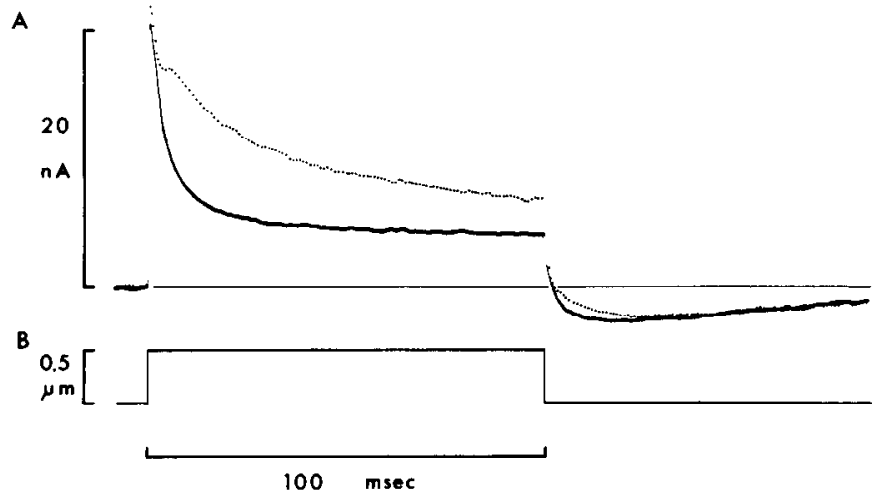

Figure 11. TEA in the lower bath. $A$, The control response is shown as a dotted line; the response with TEA is shown as a solid line. The responses are initially the same, but the TEA response continues to decline following the initial drop, whereas the control shows a bump and a recovery. The effect was fully reversible when normal perilymph was restored. Microphonic current was recorded with an uncompensated voltage clamp. $B$, Stimulus trace. The control was obtained using normal endolymph and normal perilymph; TEA perilymph contained $2 \mathrm{~mm}$ tetraethylammonium chloride; all solutions were at $22.0^{\circ} \mathrm{C}$.

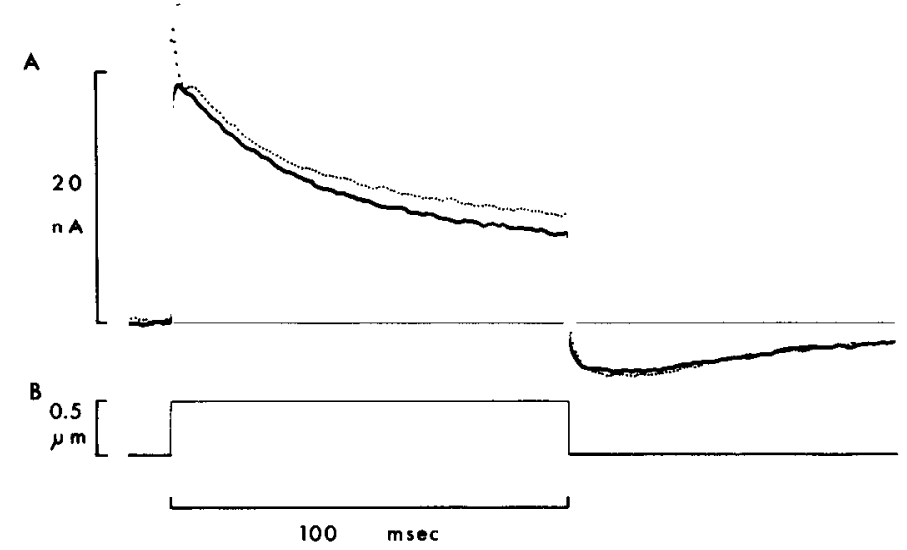

Figure 12 . High $\mathrm{K}^{+}$in the lower bath. $A$, The control reponse is shown as a dotted line; the response with high $\mathrm{K}^{+}$is shown as a solid line. The initial amplitude is smaller with high $\mathrm{K}^{+}$, but the response has a smooth decline which nearly matches that of the control in the latter part of the step. Microphonic current was recorded with an uncompensated voltage clamp. $B$, Stimulus trace. The control was obtained using normal endolymph and normal perilymph; for high $\mathrm{K}^{+}$perilymph a portion of the $\mathrm{Na}^{+}$was substituted with $\mathrm{K}^{+}$to bring the $\mathrm{K}^{+}$concentration to $17 \mathrm{mM}$. All solutions were at $22.0^{\circ} \mathrm{C}$. 
ent conductances. A response waveform of this sort is seen also when the transepithelial resistance is particularly low, presumably because $\mathrm{K}^{+}$from the endolymph is leaking through tight junctions to elevate the peribasal $\mathrm{K}^{+}$concentration. When this occurs, the response waveform can be restored to normal by substituting a $\mathrm{Na}^{+}$ endolymph in the upper bath, as $\mathrm{Na}^{+}$may leak through but will not depolarize.

Even with a high $\mathrm{K}^{+}$concentration in the lower bath, there is a slow decline in the microphonic current during the step. Under these conditions, in which the membrane potential is virtually clamped by the high $\mathrm{K}^{+}$conductance, it seems this sag could come only from the properties of the transduction channels. One possibility is an inactivation process, whereby channels spontaneously close or are blocked following activation, much like $\mathrm{Na}^{+}$ channels in nerve (Hodgkin and Huxley, 1952). In this case, a further displacement would have no effect: the channels would be closed and would have to recover from inactivation before reopening. Another possibility is that the displacement of the hair bundle is somehow not communicated to the transduction element in a constant manner, that something in the transduction process feeds back to reduce the bias on the transduction element. If this were so, a further positive displacement of the hair bundles would reopen channels and would restore the original hair cell current.

In Figure 13, a saturating positive displacement is applied at various times before and during the step. The membrane potential is held nearly constant with high $\mathrm{K}^{+}$ in the lower bath. While the microphonic current declines during a maintained step, the current in response to a saturating positive displacement is nearly unchanged. Similarly, a saturating negative displacement decreases the current to about the same level at all times. Thus the total number of activatable channels is apparently unchanged, but the bias on them-how the bundle position is communicated to the transducer-is being reset.

A simple explanation, that the bias reset is merely the otolithic membrane slipping relative to the stimulus probe, was tested by optically monitoring otolithic membrane position. The optical signal follows the probe motion and shows no relaxation during the step (Corey and Hudspeth, 1983). Nor is there slippage between the otolithic membrane and hair bundles: the effect is seen with intracellular recording and direct stimulation of single cells (Eatock et al., 1979).

The phenomenon is further elucidated with the experiments of Figure 14. Here, as in Figure 4, the instantaneous displacement-response relation is mapped with a series of short steps of different amplitudes. A control series done before a 100-msec step shows the normal displacement-response curve. A series done near the end of the maintained displacement, however, reveals that the curve has shifted along the displacement axis. Following the step, the curve relaxes back to the resting position (data not shown). Thus channels close during a maintained positive step, not because they are inactivating, but because the displacement-response curve is, in a sense, shifting out from under them.

This shift of the displacement-response curve constitutes an adaptation mechanism for hair cells (Eatock et al., 1979). Following large positive or negative displace-

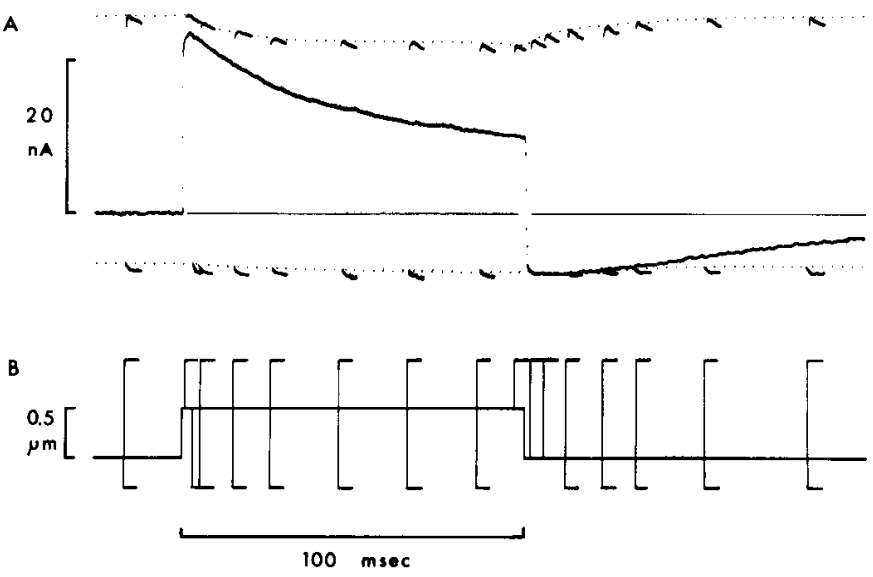

Figure 13. Saturating steps to test the maximum receptor current. $A$, The position of the normal response curve within the envelope defined by positive and negative saturations indicates the proportion of channels open. Initially, some $20 \%$ of channels are open. The $0.5-\mu \mathrm{m}$ step raises the proportion to about $90 \%$, but the proportion decreases during the maintained displacement. At the termination of the step, the proportion drops to 0 and then recovers to the initial condition over the next $100 \mathrm{msec}$ or so. Note also that the difference between negative and positive saturation envelopes changes only slightly. The net envelope indicates the maximum current through transduction channels; since the reversal potential for the receptor current is $\sim 0 \mathrm{mV}$, the net envelope is proportional to the membrane potential. It changes only slightly during the step when high $\mathrm{K}^{+}$is in the lower bath. Microphonic current was recorded with an uncompensated voltage clamp. Normal endolymph and high- $\mathrm{K}^{+}$perilymph were at $22.0^{\circ} \mathrm{C}$. B, A normal $0.5-\mu \mathrm{m}, 100-\mathrm{msec}$ step stimulus is presented, but at a given time during the step the probe is further stepped to $+1.0 \mu \mathrm{m}$ or -0.3 $\mu \mathrm{m}$. These saturating displacements should open or close, respectively, virtually all of the available channels. One saturating step is presented with each normal stimulus; the figure is a composite of 29 different presentations.

ments of the hair bundle, which move the bundle out of the responsive range, the adaptive shift acts to move the range to the new bundle position. Hair cells thus maintain a large operating range while retaining high sensitivity to small displacements. For small stimuli, the shift acts as a high-pass filter; it is largely responsible for the highpass filtering and phase lead shown in Figure 5.

Adaptation also explains the form of the undershoot following the step. At rest, about $20 \%$ of the mechanically activatable transduction channels are open; the transepithelial current includes this steady component. With a maintained positive displacement, the displacement-response curve shifts to the right. Then, when hair bundles are moved back, they move to a portion of the curve where no channels are open: the current becomes less than the resting current. Finally, as the curve relaxes back to the rest position, a portion of the current returns.

Our understanding of these various effects may be summarized with Figure 15, which shows a saturating step experiment like that of Figure 13 but in a normal ionic environment. The figure provides two measures of processes occurring within the hair cells. The difference between positive saturation and negative saturation reflects the maximum possible receptor current and is proportional to the potential across the apical membrane. 

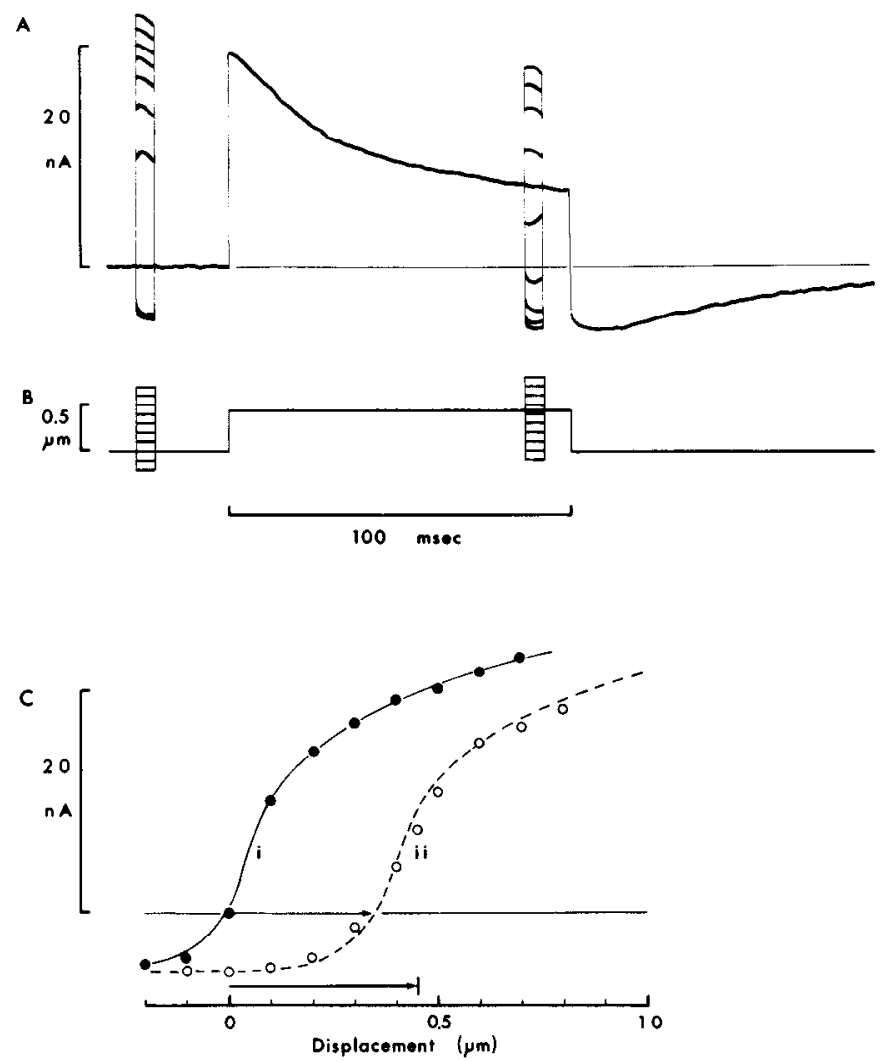

Figure 14. Step series to map the displacement-response curve. The same conditions as in Figures 12 and 13 were used. $A$, The superimposed response to test steps presented before the normal stimulus shows saturation with large positive steps. Near the end of the maintained step stimulus, however, the same positive steps evoke less current and the negative saturation is more pronounced. $B$, Superimposed on the normal $0.45-\mu \mathrm{m}$ stimulus are fast test steps of varying amplitude, presented either before or near the end of the stimulus. Again, one test step was presented with each normal stimulus; the figure is a composite of 20 presentations. $C$, The displacement-response curves generated in $A$ and $B$ are plotted. Ninety milliseconds after the onset of a $0.45-\mu \mathrm{m}$ step, the control curve (i) has been shifted along the displacement axis by $0.33 \mu \mathrm{m}$ (ii); the amplitude is unchanged. Curves were drawn by eye with reference to Figure 4.

The position of the response curve within this envelope shows the proportion of channels open and thus continuously indicates the position of the displacement-response curve.

The constriction of the net envelope immediately following the step indicates the intracellular depolarization, which occurs concurrently with the initial drop in the microphonic current. The bump in the microphonic current, which we attribute to a basolateral $\mathrm{K}^{+}$conductance, is followed by a slight increase in the envelope size-a slight repolarization of the membrane potential. While the envelope is relatively unchanged for the remainder of the step, the microphonic current drops steadily as the displacement-response curve shifts. At the termination of the step, the microphonic current drops to meet the lower (negative saturation) envelope: all of the transduction channels are closed. The lower envelope and the microphonic current then decline together over 5 to 10 msec as the cell membrane capacitance discharges through the slowly closing $\mathrm{K}^{+}$channels. The magnitude of the net envelope increases rapidly, however, at the termination of the step: with all transduction channels closed, the hair cell is hyperpolarized beyond the initial resting potential. The membrane potential returns gradually as the displacement-response curve recovers and a portion of the transduction channels reopens.

\section{Reconstructing the step response}

We have described several properties of hair cells that are not linear with stimulus displacement or are not constant over time, and have presented qualitative evidence to show that these properties can explain the microphonic current response to a step displacement stimulus. Our description would be strengthened considerably if it could be shown that these effects can quantitatively predict the step response. To do this, quantitative relations describing each component were combined, and a solution to the combined expressions was generated by stepwise integration with a computer. Quantitative reconstruction does in fact produce most of the characteristic features of the experimental step response.

Each of the relevant elements is described as follows. The "instantaneous" displacement-response curve is fitted by an expression of the form

$$
P_{t}=\frac{1}{1+e^{B}\left(1+e^{A}\right)}
$$

where $A=\left(G_{1}-Z_{1} x\right) / R T$ and $B=\left(G_{2}-Z_{2} x\right) / R T . P_{t}$ is the probability that a transduction channel is open, $G_{1}$ is $0.75 \mathrm{kcal} / \mathrm{mol}, G_{2}$ is $0.25 \mathrm{kcal} / \mathrm{mol}, Z_{1}$ is $10.0 \mathrm{kcal} / \mathrm{mol}-$ $\mu \mathrm{m}, Z_{2}$ is $2.0 \mathrm{kcal} / \mathrm{mol}-\mu \mathrm{m}, x$ is bundle displacement in micrometers, $R$ and $T$ have their usual thermodynamic

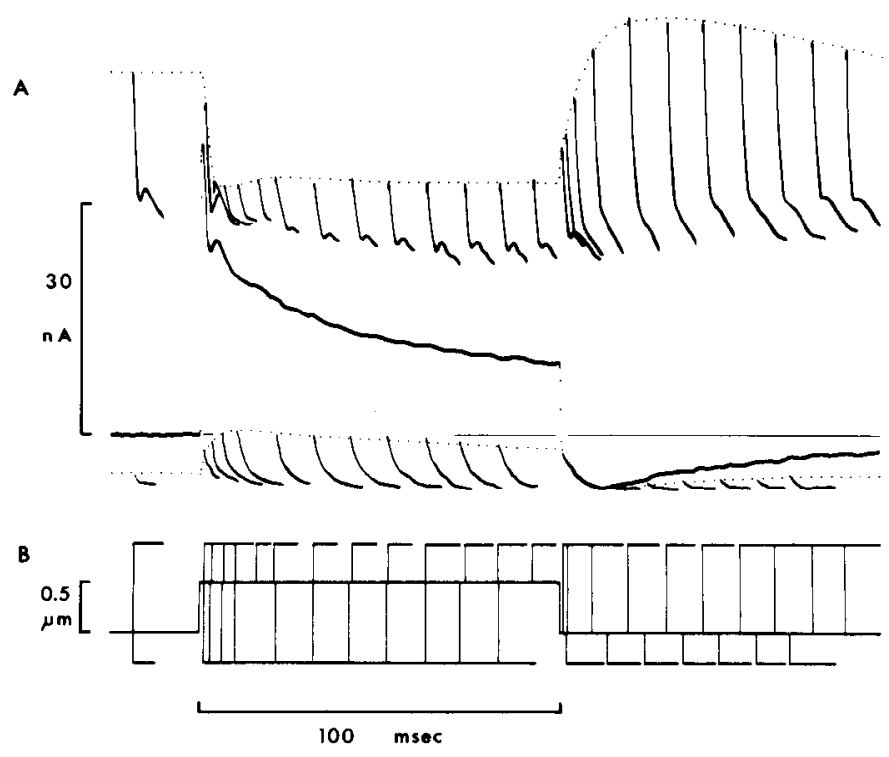

Figure 15. Saturating steps in a normal ionic environment. The stimulus is similar to that in Figure 13, but high $\mathrm{K}^{+}$ perilymph has been replaced with normal perilymph. The net envelope, proportional to the intracellular membrane potential, now shows a large change corresponding to the receptor potential. The shift of the displacement-response curve during the step is still apparent. Microphonic current was recorded with an uncompensated voltage clamp. Normal endolymph was at $22.0^{\circ} \mathrm{C}$. 
meanings, and $R T=0.586 \mathrm{kcal} / \mathrm{mol}$. The theoretical basis for this particular choice of models and experimental evidence providing the numerical values are presented elsewhere (Corey and Hudspeth, 1983). While the probability $P_{t}$ is described here as an instantaneous function of $x$, the observed relaxation to a new value has a time constant of 25 to $150 \mu \mathrm{sec}$ at $22^{\circ} \mathrm{C}$ (Corey and Hudspeth, 1983). This is sufficiently fast as to be negligible in the context of the present work.

The adaptive shift of the displacement-response curve is not a simple first-order exponential relaxation. It can be roughly fitted, however, by a sum of two exponential decays in time:

$$
x=1 / 2 x_{0}\left(e^{-t / T_{1}}+e^{-t / T_{2}}\right)
$$

where $x$ is the effective displacement communicated to the transduction element, $x_{0}$ is the initial bundle displacement at $t=0, T_{1}$ is $10 \mathrm{msec}$, and $T_{2}$ is $100 \mathrm{msec}$. This expression has no theoretical basis, but is the simplest empirical expression that fits our preliminary measurements of the adaptation (Corey, 1980). At the termination of the step, $x_{0}$ is subtracted from $x$, and each of the two components relaxes to zero with its characteristic time constant. An adaptive shift during symmetrical stimuli such as sinusoidal tone bursts suggests that the adaptation rates following positive and negative displacements differ (Corey, 1980). For simplicity, the present description assumes symmetrical rates.

The membrane capacitance and leakage resistance per area of epithelial surface are given the values calculated under "Equivalent circuit of the macular epithelium" of this paper. The latter value is assumed to be due principally to potassium conductances, as in frog nerve (Hille, 1973), so the basolateral leakage resistance is in series with a Nernst battery of $E_{\mathrm{K}}=-84 \mathrm{mV}$, but the apical leakage resistance has a series battery of $\sim 0 \mathrm{mV}$.

The reversal potential for the receptor current is $\sim 0$ $\mathrm{mV}$ and the current-voltage relation for the conductance is linear over the physiological range (Corey and Hudspeth, 1979b). The current is modulated by the probability that channels are open (the displacement-response curve), thus

$$
i_{t}=P_{t} V_{m} / R_{t}
$$

The outward rectification is more complex, as both equilibrium values and time course are continuous functions of membrane potential. Two convenient models are the voltage-sensitive potassium conductance of the squid axon (Hodgkin and Huxley, 1952) and that of the frog node of Ranvier (Hille, 1971). Neither of them, in fact, fits particularly well our preliminary measurements with the intracellular voltage clamp. Consequently, we chose expressions of the same general form, but altered parameters to fit our intracellular measurements of $\mathrm{K}^{+}$current. The probability of a potassium channel being open is

$$
P_{\mathrm{K}}=n^{4}
$$

where $n$ is the probability that a "gating particle" is in state 1 , and where two rate constants, $k_{01}$ and $k_{10}$, govern transitions between states 1 and 0 :

$$
\begin{aligned}
& k_{01}=f e^{-\left(G-\delta z F\left[V_{m}-V_{a}\right]\right) / R T} \\
& k_{10}=f e^{-\left(G+(1-\delta)_{z} F\left[V_{m}-V_{a}\right]\right) / R T}
\end{aligned}
$$

The frequency factor $f$ is taken as $k T / h=6 \times 10^{12} \mathrm{sec}^{-1}$, $G=13.8 \mathrm{kcal} / \mathrm{mol}, \delta=0.7, z=2.0$ electric charges, $V_{m}$ is membrane potential, $V_{a}$ is an "activation potential" equal to $-38 \mathrm{mV}$, and $k, T, h, F$, and $R$ have their usual thermodynamic meanings. The current through voltagesensitive potassium channels is typically close to a linear function of voltage and has been modeled as an ohmic resistance in other studies (Hodgkin and Huxley, 1952; Hille, 1971). An ohmic resistance, gated as above, adequately describes the current-voltage relation measured in hair cells (Corey and Hudspeth, 1979b), so we take the voltage-sensitive potassium current to be

$$
i_{\mathrm{K}}=P_{\mathrm{K}}\left(V_{m}-E_{\mathrm{K}}\right) / R_{\mathrm{K}}
$$

where $R_{\mathrm{K}}$ is $9.3 \mathrm{ohm}-\mathrm{cm}^{2}$ of epithelium and $E_{\mathrm{K}}$ is the potassium Nernst potential of $-84 \mathrm{mV}$. In some preparations the outward rectification appears to consist of two components, the faster of which is preferentially blocked by TEA, $\mathrm{Co}^{2+}$, and $\mathrm{Ni}^{2+}$, and the slower of which is more sensitive to 3,4-diaminopyridine. More direct experiments suggest that these correspond, respectively, to a calcium-dependent $\mathrm{K}^{+}$conductance and a voltageactivated $\mathrm{K}^{+}$conductance (Lewis, 1982). It is the summed behavior of these two components we have modeled above.

We have some evidence for other membrane conductances in hair cells, and these doubtless contribute to the response. There is a voltage-sensitive $\mathrm{Ca}^{2+}$ conductance in the basolateral membrane (Hudspeth and Corey, 1977; Lewis, 1982), probably involved with $\mathrm{Ca}^{2+}$-dependent transmitter release. An anomalous or inward rectification is activated at membrane potentials more negative than $-100 \mathrm{mV}$ (Corey and Hudspeth, 1979b). If this is like other inwardly rectifying conductances, which turn on at less negative potentials when the extracellular $\mathrm{K}^{+}$concentration is raised (Hagiwara and Yoshii, 1979), then it is not significant under normal physiological conditions but becomes so with high $\mathrm{K}^{+}$in the lower bath. We have no evidence for voltage-sensitive $\mathrm{Na}^{+}$channels, and we expect that the efferent synapses on hair cells are not active in the in vitro preparation. These other conductances are not modelled in the reconstruction, both because we have scant quantitative understanding of them and because the reconstruction is acceptably close to the experimental results even without their inclusion.

The results of this reconstruction are shown in Figure 16. The predicted response waveforms are for the most part identical to the measured responses, with some minor deviations. The initial peak is not so large in the reconstructed waveform as is sometimes measured, suggesting that the real resting potential is more negative (and thus the initial current larger) than the model predicts. In Figure 16D, the upper envelope is not quite the same in form as the measured response for the first few milliseconds after the step. The rebound phenomena in that trace, on the other hand, are predicted rather well by the model. Although this model is clearly preliminary-it does not include some conductances of the hair cell membrane and describes others on the basis of limited voltage clamp data-it seems to describe sufficiently well the major factors that generate the microphonic response to a step stimulus. 


\section{A}

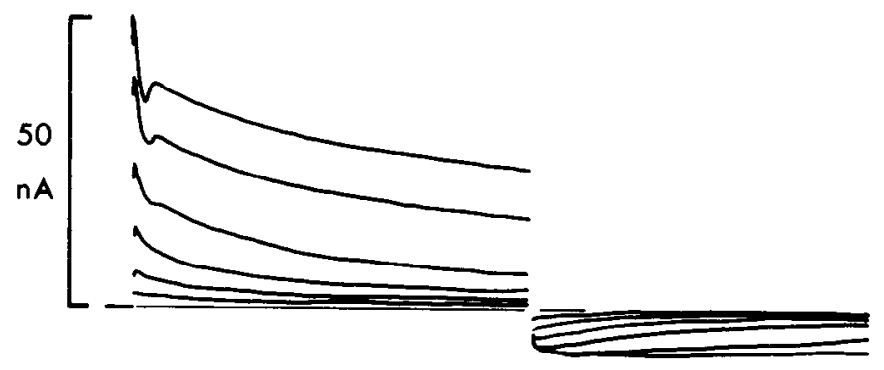

C

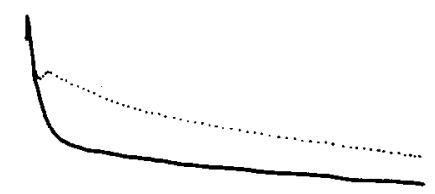

B

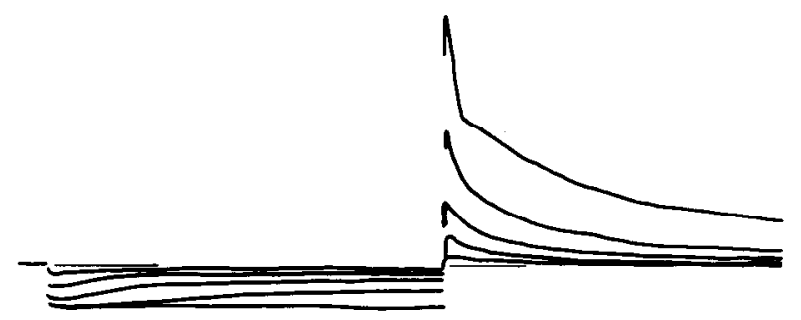

D

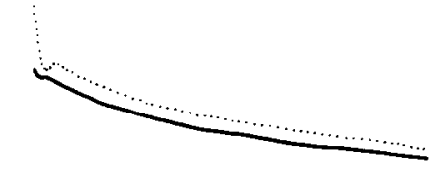

$\mathbf{F}$

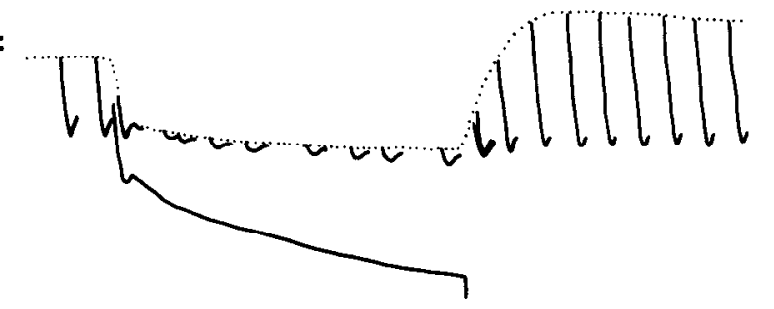

H
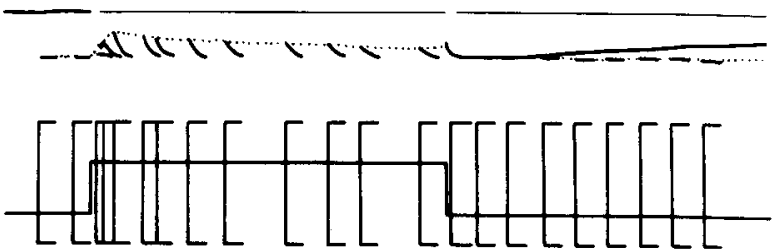

Figure 16. Results of the computer simulation of experimental records with various ionic conditions represented by altering the appropriate parameters in the computer program. $A$ and $B$, Responses to positive and negative steps, respectively, of $0.02,0.05$, $0.1,0.2,0.5$, and $1.0 \mu \mathrm{m}$ (compare Fig. 10). $C$, Response to a $+0.5-\mu \mathrm{m}$ step; the effect of TEA perilymph is modeled by setting $R_{\mathrm{K}}$ equal to 100 times its normal value (compare Fig. 11). $D$, Response to a $+0.5-\mu \mathrm{m}$ step; the effect of high $\mathrm{K}^{+}$in the lower bath is duplicated by adjusting $E_{\mathrm{K}}$ to $-50 \mathrm{mV}$ (compare Fig. 12). $E$, Response to a $+0.45-\mu \mathrm{m}$ step with test steps to various levels before the stimulus step and after $90 \mathrm{msec}$. High $\mathrm{K}^{+}$perilymph was again simulated by changing $E_{\mathrm{K}}$ to $-50 \mathrm{mV}$ (compare Fig. 14). $F$, Response to a $+0.5-\mu \mathrm{m}$ step with test steps at various times to $+1.0 \mu \mathrm{m}$ or $-0.5 \mu \mathrm{m}$ (compare Fig. 15).

\section{Discussion}

\section{The epithelial preparation of the bullfrog's sacculus}

The bullfrog's sacculus, mounted and stimulated as the whole organ, has certain advantages as a preparation for studying transduction by hair cells. The organ is spatially homogeneous and contains predominantly a single type of hair cell. Complexities of the mammalian cochlea, such as a phase delay between regions caused by the traveling wave or differing contributions from inner and outer hair cells, are thus avoided. The complication of oppositely oriented hair cells in this preparation can be removed by peeling the otolithic membrane off most of the macula. The sacculus is also considerably more robust than the mammalian cochlea, producing large microphonic signals for as long as $8 \mathrm{hr}$ after removal from the animals. An in vitro preparation also allows more direct control and assessment of the stimulus delivered to the mechanically sensitive stereocilia. In contrast, stimulation by sound (Furukawa et al., 1972; Crawford and Fettiplace, 1981b), by water movement (Harris and van Bergeijk, 1962), or even by displacement of an attached cupula (Flock, 1965) requires certain assumptions to be made to calculate hair bundle displacement. Since the resistive pathways between apical and basal surfaces of the epithelium are clearly defined and the morphology of the tissue is sufficiently stereolyped, a detailed estimate of the equivalent circuit can be made. 
Of course, stimulation by means of the otolithic membrane and recording the transepithelial current are less direct than stimulation of and recording from single cells (Hudspeth and Corey, 1977). The advantages of the epithelial preparation with respect to single-cell experiments lie primarily in the greater stability afforded and the ability to easily superfuse separately the apical and basal surfaces of the cells. As may be seen in the following paper (Corey and Hudspeth, 1983), the far greater temporal resolution of both stimulation and recording with the epithelial preparation permits experiments directed at analyzing the fast kinetics of the transduction process.

\section{Generation of the microphonic potential}

The factors that determine the flow of current from apex to base through hair cells are largely independent of the extracellular potential that this current generates. The independence arises because the microphonic potential, usually less than a millivolt in amplitude, is small compared to the driving force for receptor current and to the sensitivity of voltage-dependent conductances in hair cell membranes. The microphonic potential is comparatively small because the resistance of extracellular current paths-in particular the tight junctions of the epithelium-is small compared to the resistance of cell membranes. This separation of hair cell current from microphonic potential has both practical and conceptual implications.

The conceptual implication is that the microphonic potential is an epiphenomenon of transduction: it is a signal of use to the electrophysiologist, but not of importance in the function of the nervous system. The receptor potential, which is the change in potential across the basolateral hair cell membrane, controls entry of $\mathrm{Ca}^{2+}$ through a voltage-dependent conductance (R. S. Lewis, A. J. Hudspeth, and D. P. Corey, unpublished observations); the change in intracellular $\mathrm{Ca}^{2+}$ most probably modulates the release of transmitter from the cell (Sand et al., 1975). These events are not dependent on the microphonic potential. The postsynaptic conductance change and the consequent initiation of impulses in the afferent nerve fibers should be similarly unaffected. It has been shown that potentials applied across epithelia containing hair cells can directly evoke activity in the afferent nerve, presumably by causing $\mathrm{Ca}^{2+}$-dependent transmitter release (Strelioff and Honrubia, 1978; Valli et al., 1979); indeed, this general mechanism underlies electrorception in ampullae of gymnotid and mormyrid fishes (Bennett, 1971). The thresholds for electrical excitation of nerve activity, however, are far higher than the microphonic potential produced by moderate mechanical stimuli. This point has been debated for some time (Davis, 1965), but until it can be shown that the microphonic potential modifies the behavior of hair cells (Strelioff et al., 1976), the microphonic potential cannot be considered a receptor potential in the strictest sense: it is not part of the sensory pathway.

The practical consequence, however, is that the analysis of the microphonic potential is simplified because the microphonic potential generated by a cell does not feed back to modify the behavior of the cell or its neighbors. With appropriate interpretation this signal can be an independent measure of events occurring in hair cells.
The interpretation is not trivial, as a number of processes contribute to the generation of the microphonic potential.

The microphonic potential is in general the product of the impedance of tissue both that is electrically between the recording electrodes and that hair cell current flows through, and of the current passing through that tissue. Importantly, the impedance has both resistive and capacitive components. Parallel capacitance in particular shapes the microphonic potential by attenuating high frequency components, an effect already recognized both in mammalian cochleas (Cannon, 1976; Geisler et al., 1977; Schmiedt and Zwislocki, 1977) and in peripheral organs (Boston, 1980). In the present preparation the tight junctional resistance in parallel with the lumped hair cell and supporting cell capacitance has a time constant of about $400 \mu \mathrm{sec}$, which produces a single-pole, low-pass filter with a corner frequency near $400 \mathrm{~Hz}$. Impedance of tissue between the electrodes but not in the current path, in this case the series resistance of the supporting cell apposition and the chamber, does not affect the microphonic potential. Similarly, the resistance measured between scala media (SM) and scala tympani (ST) of the first turn of the guinea pig cochlea is 3.5 to 9.8 kilohms (Sitko et al., 1973; Cannon, 1976; Geisler et al., 1977) and the capacitance is 60 to $90 \mathrm{nF}$ (Sitko et al., 1973; Geisler et al., 1977) predicting a corner frequency of 180 to $650 \mathrm{~Hz}$. The actual corner frequency is much higher, near $4000 \mathrm{~Hz}$ (Schmiedt and Zwislocki, 1977); the capacitance may thus be in parallel with, and the hair cell current may flow through, only a small proportion of the SM-to-ST resistance.

The microphonic potential is thus proportional to the hair cell current, but the constant of proportionalitythe tissue impedance-is frequency dependent. It is possible to correct for the transfer function of the impedance (Corey and Hudspeth, 1979a); better still is to measure the current directly by voltage-clamping the tissue.

The microphonic current, measured with a compensated transepithelial voltage clamp, is generated by processes within the hair cells. The most striking of these, and the earliest recognized, is the nonlinear displacement-response curve (Fig. 4; Jielof et al., 1952; Flock, 1965; Johnstone and Johnstone, 1965; Furukawa et al., 1972; Weiss et al., 1974); here we can measure it directly as the relation between bundle displacement and the conductance change of the apical membrane. The conductance change saturates with large negative and positive displacements, but the negative saturation occurs more abruptly and with smaller displacements. The asymmetry of the saturation produces the rectification recognized in other microphonic records. In lateral line and otolithic organs, where the microphonic potential is generated by the summed responses of oppositely oriented hair cell populations, rectification produces a component of the response at twice the frequency of the stimulus (Jielof et al., 1952; Flock, 1965). Both in these organs and in the mammalian cochlea, where hair cells are of a single polarity, filtering by the tissue capacitance reduces the oscillatory $(\mathrm{AC})$ component of the response to higher frequency stimuli, revealing a steady-state (DC) component, the summating potential (Johnstone and Johnstone, 1965). Intracellular recordings from hair cells 
exhibit the same features of the response: an asymmetric $\mathrm{AC}$ component and a DC component produced by the process of rectification and filtering (Weiss et al., 1974; Hudspeth and Corey, 1977; Russell and Sellick, 1978; Crawford and Fettiplace, 1981b).

The microphonic current is not generated solely by the change in transducer conductance, however. The changing transduction current changes the membrane potential, activating voltage-dependent conductances in the cell membrane. The resulting currents add to the recorded microphonic current. We have presented evidence for voltage-dependent $\mathrm{K}^{+}$conductances and have incorporated them in the model of the microphonic potential. We have evidence for at least two more, an inward rectification at hyperpolarized potentials (Corey and Hudspeth, 1979b) and a voltage-dependent $\mathrm{Ca}^{2+}$ conductance (Hudspeth and Corey, 1977; Lewis, 1982). Importantly, all of these conductances are not instantaneous or linear functions of potential. Moreover, currents entering through the apical or basal surfaces of hair cells contribute signals of opposite polarity to the microphonic potential. The contributions of voltage-dependent conductances to the microphonic current are correspondingly complex. If the microphonic potential is to be used as an assay of the transduction mechanism, the stimulusdependent current must be isolated from voltage-dependent currents. Here isolation is achicved by depolarization to reduce the receptor potential (Fig. 12) or by applying fast stimuli and recording current before the membrane potential changes significantly (Fig. 4; Corey and Hudspeth, 1983).

Even with such isolation, there is a time-dependent component to the microphonic potential, generated by the adaptation mechanism. Following hair bundle displacement, the effective stimulus communicated to the transduction element relaxes back toward zero over tens to hundreds of milliseconds. This mechanism, which serves to maintain hair cell sensitivity following static bundle displacements (Eatock et al., 1979), has not been reported for other hair cell organs, except insofar as it has been characterized as a phase lead in the response to sinusoidal stimuli or as a transient response (Flock, 1965; Kroese et al., 1980). The magnitude of the effect, however, may vary among hair cell organs: the adaptation rate depends on $\mathrm{Ca}^{2+}$ concentration at the apical hair cell surface (Eatock et al., 1979) and the $\mathrm{Ca}^{2+}$ concentration of endolymph varies markedly among organs and species (Bosher and Warren, 1978; Petersen et al., 1978; McGlone et al., 1979).

\section{Interpretation of microphonic recordings}

A great many studies have employed the microphonic potential as an assay for hair cell function during experimental manipulations. Applications of aminoglycoside antibiotics (Wersäll and Flock, 1964; Matsuura et al., 1971b; Bernard, 1980; Kroese and van den Bercken, 1980) or other ototoxins (Sellick and Johnstone, 1974), replacement of cations or anions in endolymph or perilymph (Konishi et al., 1966; Matsuura et al., 1971a; Sand, 1975; Corey and Hudspeth, 1979b; Valli et al., 1979), stimulation of efferent nerves (Flock and Russell, 1976; Geisler et al., 1980; Furukawa, 1981), induction of anoxia (Davis et al., 1958; Konishi et al., 1961), temperature change
(Butler et al., 1960; Werner, 1976; de Brey and Eggermont, 1978), application of external electrical fields (Honrubia and Ward, 1969), and destruction of specific populations of hair cells (Dallos and Cheatham, 1976) are some examples. Rather than commenting on specific studies, we will discuss a few instances where specific effects on hair cell properties may have indirect effects on the microphonic potential.

Change in tissue impedance. A trivial instance is a decrease in the resistance of tissue between the recording electrodes, for instance a decline in tight junction integrity. Although there may be no change in hair cell function, the amplitude of the microphonic potential would decline. Moreover, if stimulation is at frequencies near the low-pass cut-off frequency of the tissue, the resistance decrease would decrease the phase lag of the microphonic potential.

Increase in basolateral potassium conductance. Efferent stimulation may increase an acetylcholine-sensitive $\mathrm{K}^{+}$conductance in hair cells (Flock and Russell, 1976). The resultant hyperpolarization would increase the transduction current by increasing the driving force so that the microphonic amplitude would increase. Because the input resistance of the cell would be decreased, however, the receptor potential amplitude would decrease under most circumstances. Thus the effect of a manipulation on the microphonic potential may be opposite to its effect on the receptor potential and nerve activity.

In contrast, a rise in voltage-sensitive $\mathrm{K}^{+}$conductance elicited by depolarization of the cell, as caused here by a high $K^{\prime}$ perilymph, has quite a different effect. The microphonic potential decreases slightly because of the depolarization, and the receptor potential may become negligibly small. However, there may be a considerable rise in tonic nerve activity.

Shift of the displacement-response curve. The concentration of $\mathrm{Ca}^{2+}$ at the apical hair cell surface affects the resting position of the displacement-response curve (Corey and Hudspeth, 1983). Specifically, reduction of apical $\mathrm{Ca}^{2+}$ concentration increases the proportion of the transducer conductance active at rest: it shifts the displacement-response curve to the left, reducing the rectification. In the lateral line organ, whose oppositely oriented responses would cancel except for the rectification, lowered apical $\mathrm{Ca}^{2+}$ might abolish the microphonic potential although hair cells were functioning normally. With extreme shifts, the rectification would reverse, generating a $2 f$ response of opposite polarity and (incorrectly) suggesting a reversal of the receptor current. In the mammalian cochlea, the microphonic potential in response to small stimuli might increase while the summating potential disappeared. Although the underlying effect of lowered $\mathrm{Ca}^{2+}$ is simple, the observed responses could lead to considerable misinterpretation.

Reduction of the adaptation rate. Adaptation constitutes a high-pass filter, with the apparent cut-off frequency a function of the adaptation rate. The rate is sensitive to several manipulations, including temperature change and altered apical $\mathrm{Ca}^{2+}$ concentration (Eatock et al., 1979). If the effect of a drug under test were to decrease the rate, lowering the apparent cut-off frequency, the drug would act to increase the amplitude of 
the microphonic potential evoked by low frequency stimuli though the transducer sensitivity was unchanged. In addition, the phase lead caused by adaptation would be reduced.

In each of these instances, difficulties in interpretation can be avoided by appropriate stimulation and recording. When the transepithelial current is measured directly with a voltage clamp, changes in epithelial resistance are inconsequential. The waveform of the response to step stimuli can indicate changing membrane conductances, and the size of the receptor potential may be estimated by presenting saturating step stimuli (Fig. 13). If the stimulus is restricted to cells of a single orientation, the displacement-response curve may be measured directly with a series of step displacements. Mapping the displacement-response curve before and during stimulation provides an independent measure of the adaptation.

\section{Adequacy of the model}

As Dallos (1981) has pointed out, the past few years have seen an explosion of modeling of vertebrate auditory and vestibular responses. While presentation of a model here is intended principally to show that we can predict the responses we see with the elements we suppose are present, the model would be of little use if it did not also predict responses in other systems. For the most part, it does.

Microphonics produced by continuous sinusoidal stimulation of lateral line or otolithic organs (Flock, 1965; Furukawa et al., 1972; Boston, 1980; Kroese et al., 1980) can be adequately described by this model. Accurate fits of the phase require the supposition that lateral line organs have about twice the epithelial time constant of the bullfrog's sacculus and that the goldfish's sacculus in vivo has about half. The model does not adequately deal with a slow decline in the response to tone bursts seen in this preparation or elsewhere (Boston, 1980; Kroese et al., 1980). Preliminary experiments suggest that there is an unequal rate of adaptation following positive or negative displacements, such that the transducer conductance decreases during a symmetrical tone burst (Corey, 1980). Although the effect is not included in this simple model, it would explain the responses.

The model also fits intracellular responses recorded in this preparation and in others (Mulroy et al., 1974; Hudspeth and Corey, 1977; Crawford and Fettiplace, 1981b). To fit lizard cochlear hair cells, the input resistance must be decreased and the displacement-response curve must be shifted to the right. To fit the responses of turtle cochlear hair cells that are seen when TEA is added to the saline, the voltage-dependent $\mathrm{K}^{+}$conductance is (not surprisingly) set equal to zero. Matching the sensitivity of the turtle pressure-response curve requires a conversion of $0.01 \mu \mathrm{m} / \mathrm{Pa}$, about twice the figure estimated by Crawford and Fettiplace (1980). Neither of these fits provides a particularly stringent test of the model, as the $\mathrm{K}^{+}$conductance is inconsequential in both cases, and the stimuli are too fast to elicit much adaptation.

The saccular model with the parameters employed here fails to reproduce the oscillatory behavior observed in turtle hair cells (Crawford and Fettiplace, 1981a) and we measured no frequency tuning under the present experimental circumstances. Conversely, the model of
Crawford and Fettiplace (1981b), lacking adaptation by hair cells, cannot fit the responses seen here with step stimuli.

\section{Reassessment of the Davis theory}

The essence of Davis' (1965) theory of the cochlear microphonic potential is that stimulation causes a resistance change of the apical hair cell membrane, which modulates current driven by the potential difference across the apical membrane. The microphonic potential is derived from the modulated current. The theory, elements of which were first proposed in 1953 (Davis, 1953), has been challenged by recent electrophysiological findings (Leng, 1980). In general, the challenges are of two sorts. Some argue that the transduction conductance does not directly modulate a current flow through hair cells, that the basic mechanism proposed is incorrect. Others suggest that the modulation of resistance does not fully explain the microphonic potential, that other processes are involved as well. Since the Davis theory has served as a focus for discussion in auditory research for so long, it is worth commenting on how these findings relate to it.

Russell and Sellick (1978), in recording intracellularly from guinea pig inner hair cells, measured a stimulusdependent resistance change corresponding to the receptor potential, and found that the change in input resistance of the cell was proportional to the change in membrane potential. They argued that this implied a constant current through hair cells, which would cast doubt on Davis' notion of a modulated current. While the proportionality does suggest a constant current, it is also perfectly compatible with a current modulated by a resistance change: the experiment cannot distinguish between them (Weiss et al., 1981). A stimulus-dependent conductance change has now been observed with intracellular recording from hair cells of amphibians (Hudspeth and Corey, 1977), reptiles (Crawford and Fettiplace, 1981b), and mammals (Russell and Sellick, 1978), and the modulated receptor current has been measured directly with voltage clamp of single cells (Corey and Hudspeth, 1979b). There can be little doubt that this part of the theory is essentially correct. Interestingly, the transducer is not selective among small cations (Corey and Hudspeth, 1979b); thus, in most ionic environments the current reverses with approximately $0 \mathrm{mV}$ across the apical membrane. Such a conductance is a nearly perfect biological correlate of Davis' variable resistor.

Geisler et al. (1980) measured harmonic components of both the cochlear microphonic potential and the resistance change between scala media and scala tympani of guinea pig cochlea. Under certain conditions, such as anoxia or applied currents, the microphonic potential and the resistance change do not agree well. They point out that many of their results could be explained by supposing a nonlinear resistance and suggest specifically a voltage-dependent inward rectification in the basolateral hair cell membrane.

We describe here two other elements that appear to contribute to the microphonic potential-the outwardly rectifying $\mathrm{K}^{+}$conductance and the adaptive shift-and others will doubtless be added as hair cells become better understood. While such processes were not described in 
Davis' theory, they were never ruled out. Indeed it would have been surprising had the theory not required expansion with time.

\section{References}

Adrian, E. D. (1928) The Basis of Sensation, Christophers, London.

Adrian, E. D. (1931) The microphonic action of the cochlea: An interpretation of Wever and Bray's experiments. J. Physiol. (Lond.) 71: xxviii-xxix.

Bennett, M. V. L. (1971) Electroception. In Fish Physiology, Vol. 5, W. S. Hoar and D. J. Randall, eds., pp. 493-574, Academic Press, Inc., New York.

Bernard, C. (1980) Electrical activity of isolated semicircular canal in the frog: Action of streptomycin. Pflügers Arch. 388: 93-99.

Bezanilla, F., and C. M. Armstrong (1972) Negative conductance caused by entry of sodium and cesium ions into the potassium channels of squid axons. J. Gen. Physiol. 60: 588608.

Bosher, S. K., and R. L. Warren (1978) Very low calcium content of cochlear endolymph, an extracellular fluid. Nature 273: $377-378$.

Boston, J. R. (1980) A model of lateral line microphonic response to high-level stimuli. J. Acoust. Soc. Am. 67: 875-881.

Butler, R. A., T. Konishi, and C. Fernandez (1960) Temperature coefficients of cochlear potentials. Am. J. Physiol. 199: 688692.

Cannon, M. W. (1976) Electrical impedances, current pathways and voltage sources in the guinea pig cochlea. Special Report ISR-5-14, Institute for Sensory Research, Syracuse University, Syracuse, NY.

Clausen, C., S. A. Lewis, and J. M. Diamond (1979) Impedance analysis of a tight epithelium using a distributed resistance model. Biophys. J. 26: 291-318.

Corey, D. P. (1980) A biophysical approach to sensory transduction by vertebrate hair cells. Doctoral thesis, California Institute of Technology, Pasadena, CA.

Corey, D. P., and A. J. Hudspeth (1979a) Response latency of vertebrate hair cells. Biophys. J. 26: 499-506.

Corey, D. P., and A. J. Hudspeth (1979b) Ionic basis of the receptor potential in a vertebrate hair cell. Nature 281: 675677.

Corey, D. P., and A. J. Hudspeth (1980) Mechanical stimulation and micromanipulation with piezoelectric bimorph elements. J. Neurosci. Methods 3: 183-202.

Corey, D. P., and A. J. Hudspeth (1983) Kinetics of the receptor current in bullfrog saccular hair cells. J. Neurosci. 3: 962-976.

Crawford, A. C., and R. Fettiplace (1980) The frequency selectivity of auditory nerve fibres and hair cells in the cochlea of the turtle. J. Physiol. (Lond.) 306: 79-125.

Crawford, A. C., and R. Fettiplace (1981a) An electrical tuning mechanism in turtle cochlear hair cells. J. Physiol. (Lond.) 312: 377-422.

Crawford, A. C., and R. Fettiplace (1981b) Nonlinearities in the responses of turtle hair cells. J. Physiol. (Lond.) 315: 317-338.

Dallos, P. (1973) The Auditory Periphery, Academic Press, Inc., New York.

Dallos, P. (1981) Cochlear physiology. Annu. Rev. Psychol. 32: 153-190.

Dallos, P., and M. A. Cheatham (1976) Production of cochlear potentials by inner and outer hair cells. J. Acoust. Soc. Am. 60: $510-512$

Davis, H. (1953) Energy into nerve impulses: Hearing. Med. Bull. St. Louis Univ. 5: 43-48.

Davis, H. (1965) A model for transducer action in the cochlea. Cold Spring Harbor Symp. Quant. Biol. 30: 181-190.

Davis, H., B. H. Deatherage, B. Rosenblut, C. Fernandez, R.
Kimura, and C. A. Smith (1958) Modification of cochlear potentials produced by streptomycin poisoning and by extensive venous obstructions. Laryngoscope 68: 596-627.

de Brey, H. B., and J. J. Eggermont (1978) The influence of cochlear temperature on the electrical travelling wave pattern in the guinea pig cochlea. Acta Otolaryngol. 85: 363-371.

de Vries, H., and J. D. J. W. Blecker (1949) The microphonic activity of the labyrinth of the pigeon. II. The response of the cristae in the semicircular canals. Acta Otolaryngol. 37: 298-306.

Eatock, R. A., D. P. Corey, and A. J. Hudspeth (1979) Adaptation in a vertebrate hair cell: Stimulus-induced shift of the operating range. Soc. Neurosci. Abstr. 5: 19.

Eaton, D. C. (1972) Potassium ion accumulation near a pacemaking cell of Aplysia. J. Physiol. (Lond.) 224: 421-440.

Flock, A. (1965) Electron microscopic and electrophysiological studies on the lateral line canal organ. Acta Otolarymgol. (Suppl.) 199: 1-90.

Flock, $\AA$., and I. Russell (1976) Inhibition by efferent nerve fibers: Action on hair cells and afferent synaptic transmission in the lateral line canal organ of the burbot Lota lota. J. Physiol. (Iond.) 257: 45-62.

Flock, $\AA$., and J. Wersäll (1962) A study of the orientation of the sensory hairs of the receptor cells in the lateral line organ of fish, with special reference to the function of the receptors. J. Cell Biol. 15: 19-27.

Furukawa, T. (1981) Effects of efferent stimulation on the saccule of goldfish. J. Physiol. (Lond.) 315: 203-215.

Furukawa, T., and Y. Ishii (1967a) Effects of static bending of sensory hairs on sound reception in the goldfish. Jpn. J. Physiol. 17: 572-588.

Furukawa, T., and Y. Ishii (1967b) Neurophysiological studies on hearing in goldfish. J. Neurophysiol. 30: 1377-1403.

Furukawa, T., Y. Ishii, and S. Matsuura (1972) An analysis of microphonic potentials of the sacculus of goldfish. Jpn. J. Physiol. 22: 603-616.

Geisler, C. D., D. C. Mountain, A. E. Hubbard, H. O. Adrian, and A. Ravindran (1977) Alternating electrical-resistance changes in the guinea-pig cochlea caused by acoustic stimuli. J. Acoust. Soc. Am. 61: 1557-1566.

Geisler, C. D., D. C. Mountain, and A. E. Hubbard (1980) Sound-induced resistance changes in the inner ear. J. Acoust. Soc. Am. 67: 1729-1735.

Hagiwara, S., and M. Yoshii (1979) Effects of internal potassium and sodium on the anomalous rectification of the starfish egg as examined by internal perfusion. J. Physiol. (Lond.) 292: 251-265.

Harris, G. G., and W. A. van Bergeijk (1962) Evidence that the lateral-line organ responds to near-field displacements of sound sources in water. J. Acoust. Soc. Am. 34: 1831-1841.

Hille, B. (1971) Voltage clamp studies on myelinated nerve fibers. In Biophysics and Physiology of Excitable Membranes, W. J. Adelman, ed., pp. 230-246, Van Nostrand Reinhold, New York.

Hille, B. (1973) Potassium channels in myelinated nerve: Selective permeability to small cations. J. Gen. Physiol. 61: 669-686.

Hodgkin, A. L., and A. F. Huxley (1952) A quantitative description of membrane current and its application to conduction and excitation in nerve. J. Physiol. (Lond.) 117: 500-544.

Honrubia, V., and P. H. Ward (1969) Dependence of the cochlear microphonics and the summating potential on the endocochlear potential. J. Acoust. Soc. Am. 46: 388-392.

Hubbard, A. E., D. C. Mountain, and C. D. Geisler (1979) The spectral content of the cochlear microphonic measured in scala media of the guinea pig cochlea. J. Acoust. Soc. Am. 66: $415-430$.

Hudspeth, A. J. (1982) Extracellular current flow and the site of transduction by vertebrate hair cells. J. Neurosci. $2:$ 1-10. 
Hudspeth, A. J., and D. P. Corey (1977) Sensitivity, polarity, and conductance change in the response of vertebrate hair cells to controlled mechanical stimuli. Proc. Natl. Acad. Sci. IJ. S. A. 74: 2407-2411.

Hudspeth, A. J., and R. Jacobs (1979) Stereocilia mediate transduction in vertebrate hair cells. Proc. Natl. Acad. Sci. U. S. A. 76: 1506-1509.

Jielof, R., A. Spoor, and H. L. de Vries (1952) The microphonic activity of the lateral line. J. Physiol. (Lond.) 116: 137-157.

Johnstone, J. R., and B. M. Johnstone (1965) Origin of summating potential. J. Acoust. Soc. Am. 40: 1405-1413.

Konishi, T., R. A. Butler, and C. Fernandez (1961) Effects of anoxia on cochlear potentials. J. Acoust. Soc. Am. 33: 349355.

Konishi, T., E. Kelsey, and G. T. Singleton (1966) Effects of chemical alteration in the endolymph on the cochlear potentials. Acta Otolaryngol. 62: 393-404.

Kroese, A. B. A., and J. van den Bercken (1980) Dual action of ototoxic antibiotics on sensory hair cells. Nature 283: 395 397.

Kroese, A. B. A., J. M. van der Zalm, and J. van den Bercken (1980) Extracellular receptor potentials from the lateral-line organ of Xenopus laevis. J. Exp. Biol. 86: 63-77.

Leng, G. (1980) The Davis theory: A review, and implications of recent electrophysiological evidence. Hear. Res. 3: 17-25.

Lewis, R. S. (1982) Characterization of voltage- and ion-dependent conductances in vertebrate hair cells. Soc. Neurosci. Abstr. 8: 728 .

Lowenstein, O., and J. Wersäll (1959) A functional interpretation of the electron-microscopic structure of the sensory hairs in the cristae of the elasmobranch Raja clavata in terms of directional sensitivity. Nature 184: 1807-1808.

Matsuura, M., K. Ikeda, and T. Furukawa (1971a) Effects of $\mathrm{Na}^{+}, \mathrm{K}^{+}$, and ouabain on microphonic potentials of the goldfish inner ear. Jpn. J. Physiol. 21: 563-678.

Matsuura, S., K. Ikeda, and T. Furukawa (1971b) Effects of streptomycin, kanamycin, quinine, and other drugs on the microphonic potentials of goldfish sacculus. Jpn. J. Physiol. 21: 579-590.

McGlone, F. P., I. J. Russell, and O. Sand (1979) Measurement of calcium ion concentrations in the lateral line cupulae of Xenopus laevis. J. Exp. Biol. 83: 123-130.

Moreno, J. H., and J. M. Diamond (1975) Cation permeation mechanisms and cation selectivity in "tight junctions" of gall bladder epithelium. In Membranes, G. Eisenman, ed., Vol. 3, pp. 383-517, Marcel Dekker, New York.

Mulroy, M. J., D. W. Altmann, T. F. Weiss, and W. T. Peake (1974) Intracellular electric reponses to sound in a vertebrate cochlea. Nature 249: 482-485.

Newman, E. B., S. S. Stevens, and H. Davis (1937) Factors in the production of aural harmonics and combination tones. J. Acoust. Soc. Am. 9: 107-118.

Peterson, S. K., L. S. Frishkopf, C. Lechène, C. M. Oman, and T. F. Weiss (1978) Element composition of inner ear lymphs in cats, lizards, and skates determined by electron probe microanalysis of liquid samples. J. Comp. Physiol. 126: 1-14.
Russell, I. J., and P. M. Sellick (1978) Intracellular studies of hair cells in the mammalian cochlea. J. Physiol. (Lond.) 284: 261-290.

Sand, O. (1975) Effects of different ionic environments on the mechano-sensitivity of lateral line organs in the mudpuppy. J. Comp. Physiol. 102: 27-42.

Sand, O., S. Ozawa, and S. Hagiwara (1975) Electrical and mechanical stimulation of hair cells in the mudpuppy. J. Comp. Physiol. 102: 13-26.

Schmiedt, R. A., and J. J. Zwislocki (1977) Comparison of sound-transmission and cochlear-microphonic characteristics in Mongolian gerbil and guinea pig. J. Acoust. Soc. Am. 61: 133-149.

Sellick, P. M., and B. M. Johnstone (1974) Differential effects of ouabain and ethacrynic acid on the labyrinthine potentials. Pflügers Arch. 352: 335-339.

Shotwell, S. L., R. Jacobs, and A. J. Hudspeth (1981) Directional sensitivity of individual vertebrate hair cells to controlled deflection of their hair bundles. Ann. N. Y. Acad. Sci. 374: 1-10.

Sitko, S. T., V. Honrubia, and D. Strelioff (1973) Electrical resistance measurements of the walls of the guinea-pig cochlear channels. J. Acoust. Soc. Am. 54: 295.

Standen, N. B., and P. R. Stanfield (1979) Potassium depletion and sodium block of potassium currents under hyperpolarization in frog sartorius muscle. J. Physiol. (Lond.) 294: 497520 .

Strelioff, D., and V. Honrubia (1978) Neural transduction in Xenopus laevis lateral line system. J. Neurophysiol. 41: 432444.

Strelioff, D., S. T. Sitko, and V. Honrubia (1976) Role of inner and outer hair cells in neural excitation. Trans. Am. Acad. Ophthalmol. Otolaryngol. 82: 322-327.

Tasaki, I., H. Davis, and D. H. Eldredge (1954) Exploration of cochlear potentials in guinea pig with a microelectrode. $\mathrm{J}$. Acoust. Soc. Am. 26: 765-773.

Taylor, R. E., F. Bezanilla, and E. Rojas (1980) Diffusion models for the squid axon Schwann cell layer. Biophys. J. 29: 95117.

Valli, P., G. Zucca, and C. Casella (1979) Ionic composition of the endolymph and sensory transduction in labyrinthine organs. Acta Otolaryngol. 87: 466-471.

Weiss, T. F., M. J. Mulroy, and D. W. Altmann (1974) Intracellular responses to acoustic clicks in the inner ear of the alligator lizard. J. Acoust. Soc. Am. 55: 606-619.

Weiss, T. F., C. L. Searle, and K. Baden-Kristensen (1981) Proportionality of intracellular resistance changes and receptor potentials in hair-cell models. Hear. Res. 4: 243-250.

Werner, Y. L. (1976) Optimal temperatures for inner-ear performance in gekkonid lizards. J. Exp. Zool. 195: 319-352.

Wersäll, J., and $\AA$. Flock (1964) Suppression and restoration of the microphonic output from the lateral line organ after local application of streptomycin. Life Sci. 3: 1151-1155.

Wever, E. G., and C. W. Bray (1930) Action currents in the auditory nerve in response to acoustical stimulation. Proc. Natl. Acad. Sci. U. S. A. 16: 344-350. 